\title{
A diagnostic decision-making protocol combines a new-generation of serological assay and PCR to fully resolve ambiguity in COVID-19 diagnosis
}

Authors: $\mathrm{Hu}$ Cheng ${ }^{1,9} \uparrow$, Hao Chen ${ }^{2} \dagger$, Yiting $\mathrm{Li}^{1} \uparrow$, Peiyan Zheng ${ }^{2}$, Dayong $\mathrm{Gu}^{3}$, Shiping $\mathrm{He}^{3}$, Dongli $\mathrm{Ma}^{4}$, Ruifang Wang, Jun $\mathrm{Han}^{5}$, Zhongxin $\mathrm{Lu}^{6}$, Xinyi Xia ${ }^{7,8}$, Yi Deng ${ }^{1,9}$, Lan Yang ${ }^{1}$, Wenwen $\mathrm{Xu}^{1}$, Shanhui $\mathrm{Wu}^{2}$, Cuiying Liang ${ }^{2}$, Hui Wang ${ }^{6 *}$, Baoqing Sun ${ }^{2 *}$, Nanshan Zhong ${ }^{2 *}$, and Hongwei $\mathrm{Ma}^{1 *}$

\section{Affiliations:}

${ }^{1}$ Division of Nanobiomedicine, Suzhou Institute of Nano-Tech and Nano-Bionics, Chinese Academy of Sciences, Suzhou, 215123, China.

${ }^{2}$ Department of Allergy and Clinical Immunology, Guangzhou Institute of Respiratory Health, State Key Laboratory of Respiratory Disease, The First Affiliated Hospital of Guangzhou Medical University, Guangzhou, 510120, China.

${ }^{3}$ Department of Clinical Laboratory, The First Affiliated Hospital of Shenzhen University Health Science Center, Shenzhen, 518035, China.

${ }^{4}$ Shenzhen Children's Hospital, Shenzhen Engineering Laboratory for High-throughput Gene Sequencing of Pathogens, Shenzhen, 518038, China.

${ }^{5}$ State Key Laboratory of Infectious Disease Prevention and Control, Collaborative Innovation Center for Diagnosis and Treatment of Infectious Diseases, National Institute for Viral Disease Control and Prevention, Chinese Center for Disease Control and Prevention, 155 Changbai Rd, Beijing 102206, China.

${ }^{6}$ Department of Medical Laboratory, The Central Hospital of Wuhan, Tongji Medical College, Huazhong University of Science and Technology, Wuhan 430014, China.

${ }^{7}$ COVID-19 Research Center, Institute of Laboratory Medicine, Jinling Hospital, Nanjing University School of Medicine, Nanjing Clinical College of Southern Medical University, Nanjing, Jiangsu 210002, China;

${ }^{8}$ Joint Expert Group for COVID-19, Department of Laboratory Medicine \& Blood Transfusion, Wuhan Huoshenshan Hospital, Wuhan, Hubei 430100, China.

${ }^{9}$ Nano Science and Technology Institute, University of science and technology of China, Suzhou 215123, China.

*Correspondence to: B.S. (sunbaoqing@vip.163.com), H.W. (2ㅏwhwh@sina.com), N.Z. (nanshan@vip.163.com), or H.M. (hwma2008@sinano.ac.cn)

$\dagger$ These three authors contributed equally. 
One Sentence Summary: Guided by atypical humoral responses in subsets of COVID-19 patients that we detected based on an innovative serological testing technology, we have developed a diagnostic protocol that offers unprecedented performance for accurate diagnosis of COVID-19 in the clinic.

\begin{abstract}
The capacity to accurately diagnosis COVID-19 is essential for effective public health measures to manage the ongoing global pandemic, yet no presently available diagnostic technologies or clinical protocols can achieve full positive predictive value (PPV) and negative predictive value (NPV) performance. Two factors prevent accurate diagnosis: the failure of sampling methods (e.g., 40\% false negatives from PCR testing of nasopharyngeal swabs) and sampling-time-dependent failures reflecting individual humoral responses of patients (e.g., serological testing outside of the sero-positive stage). Here, we report development of a diagnostic protocol that achieves full PPV and NPV based on a cohort of 500 confirmed COVID-19 cases, and present several discoveries about the sero-conversion dynamics throughout the disease course of COVID-19. The fundamental enabling technology for our study and diagnostic protocol-termed SANE, for Symptom (dpo)-Antibody-Nucleic acidEpidemiological history - is our development of a peptide-protein hybrid microarray (PPHM) for COVID-19. The peptides comprising PPHMCOVID-19 were selected based on clinical sample data, and give our technology the unique capacity to monitor a patient's humoral response throughout the disease course. Among other assay-development related and clinically relevant findings, our

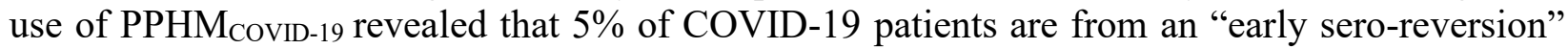
subpopulation, thus explaining many of the mis-diagnoses we found in our comparative testing using PCR, CLIA, and PPHM COVID-19. Accordingly, the full SANE protocol incorporates orthogonal technologies to account for these patient variations, and successfully overcomes both the sampling method and sampling time limitations that have previously prevented doctors from achieving unambiguous, accurate diagnosis of COVID-19.
\end{abstract}

\title{
Introduction
}

A second wave attack of severe acute respiratory syndrome coronavirus 2 (SARS-CoV-2) is expected, and the impact of the COVID-19 pandemic is predicted to last for decades (1). Therefore, there is an urgent need to review currently available diagnostic tools and use insights from such consideration to clarify the aims for new tool development (2). We believe that currently used diagnostic tools fall short in effectively containing the spread of the virus for at least two reasons: sampling-method- and sampling-time-related problems.

First, although used as the first choice and diagnostic gold standard, polymerase chain reaction (PCR)-based assays have unacceptably high rates of false negatives, i.e., approaching 40\%, for detection of SARS-CoV-2 through non-invasive sampling methods such as nasopharyngeal swabs $(3,4)$. Non-invasive sampling has a strong potential to fail in the detection of silent spreaders (i.e., subjects who are asymptomatic or in the incubation period) of the virus. Specifically, negative PCR results can only be rigorously confirmed by invasive sampling, which is unlikely in asymptomatic subjects, given the current need for massive screening efforts at population scale. Such sampling-method-related problems cannot be improved through the detection technology, i.e., PCR technology itself. 
Second, while it is the case that current serological assays have fewer problems than PCR-based methods from sampling-method-related artifacts, serological assays have stringent sampling time requirements that must fulfill well-defined criteria for successful confirmation of SARS-CoV-2 infection $(5,6)$. Consider that the period of immunoglobulin-G $(\mathrm{IgG})$ production is typically very long for most patients, and these hosts remain sero-positive as they acquire immunity $(7,8)$. Thus, serological assays can capture information throughout the viral clearance period, when PCR-based assays would fail for accurate disease diagnosis by often yielding false negatives (9).

However, when sampling during the window period, serological assays can and do report false negative results $(5,9)$. These kinds of sampling-time-related problems can be partially improved through advancement of detection technologies. It should also be emphasized that serological assays have major issues connected to the selection and use of cut-off values: one must sacrifice sensitivity to achieve high specificity, or vice versa $(10,11)$. Thus, in present practice serological assays are generally only used to obtain sero-epidemiological data, rather than for screening in public health and clinical management (12).

As sampling-(method and time)-related problems cannot be fully resolved by diagnostic kits through technical means, achieving full sensitivity and specificity is not possible using currently available diagnostic kits; consequently, the need to conduct screening in low prevalence area remains unfulfilled (13). Recently, in a discovery phase trial using a small cohort of COVID-19 patients, we developed a peptide-protein hybrid microarray (PPHM) (14)that defines cut-off values in a fundamentally distinct manner from current serological assays such as lateral flow assays (15), enzyme-linked immunosorbent assays (ELISA) (10), and chemiluminescent immunoassays (CLIA) (11)(hereafter collectively referred to as "whole-protein-based assays").

In the present study, we continue the development of this PPHM-based platform through the training and validation phases, using a large cohort of 500 COVID-19 cases. Our design for

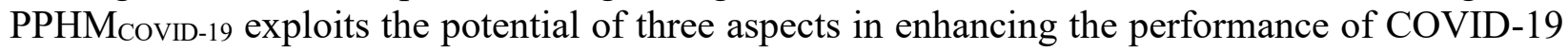
diagnosis: i) a new way to select cut-off values; ii) differences in the IgG sero-dynamics of peptides vs. receptor binding domain (RBD) of spike protein; iii) a diagnostic decision-making protocol that enables full resolution of currently difficult diagnosis ambiguities in COVID-19 and that achieves full PPV and NPV performance; we term this protocol "symptom (dpo)antibody-nucleic acid-epidemiological history" (SANE).

\section{Results}

PPHM defines cut-off values independent of the probe(s) and population(s) used in assay development

To empirically illustrate the challenges from sensitivity and specificity issues for selecting a suitable cut-off value for whole-protein-based assays, we used the SARS-CoV-2 RBD and N proteins in a microarray as discrete ELISA probes since our microarrays can be used in a full PPHM configuration or as discrete ELISA probes. The cut-off values were determined by first conducting tests in a training group that consisted of 333 control samples and 289 positive serum samples from PCR confirmed COVID-19 patients (sampled between March $6^{\text {th }}$ and $24^{\text {th }}$ ) (Fig. $1 \mathrm{~A}$, numbers in red and green, and Table S1); following typical practice, a signal value within the gray area was then selected as the cut-off value (Fig. 1C-F). The sensitivity and specificity were coupled through the cut-off value: that is, as the cut-off value was increased from 5 to 10 there 
was a decrease in the detection sensitivity of anti-RBD IgG from $85.8 \%$ to $85.1 \%$, and a further increase in the cut-off value up to 20 dropped the sensitivity down to $82.0 \%$. Moreover, these increases in cut-off value increased the specificity from $88.6 \%$ up to $99.4 \%$ (Fig. 1D).

Our data from these assays also emphasized that the cut-off value is heavily influenced by the particular population used for assay development. That is, for a serum subgroup of the training cohort that contained 106 COVID-19 and 38 control serum samples, anti-RBD IgG achieved 93.4\% sensitivity and 94.7\% specificity at a cut-off value of 20 (Fig. 1E). The absolute range of gray area and optimal cut-off value are also probe-dependent. For example, at a cut-off value of 10, anti-RBD IgG achieved $85.1 \%$ sensitivity and $98.8 \%$ specificity, while anti-(N protein) $\operatorname{IgG}$ achieved $94.8 \%$ sensitivity and $73.0 \%$ specificity (Fig. 1D, F and Fig. S1). Fundamentally, these results demonstrate that sensitivity and specificity are wholly dependent on cut-off value; and a practical implication of this fact is that assay developers must assess and explicitly account for population-specific impacts because we can now see that population characteristics obviously affect assay performance.

Seeking to resolve these cut-off value related issues affecting whole-protein-based assays, we developed a PPHM platform (Table S2) that defines cut-off values independent of i) the particular PPHM probes in the assay and ii) the population used in assay development. More specifically, PPHM employs two cut-off values: one at the individual probe level and the other at the whole microarray level. First, the cut-off value at the individual probe level in a PPHM is determined using a blank control. For example, when RBD (as a whole protein) was included as a probe for PPHM COVID-19, we detected response rates of $85.1 \%$ and $1.2 \%$ for COVID-19 and control samples, respectively (using a fixed and uniform cut-off value of 10) (Fig. 1G-H). Under this definition, a positive signal reveals the presence of IgGs in the tested serum that can recognize a PPHM probe, regardless of specificity (17).

For the second, whole-microarray-level cut-off value, we developed a Digital Microarray Index (DMI). This index represents the overall PPHM signal, and can be used to reliably determine if a tested serum sample is positive or negative for anti-(SARS-CoV-2) IgGs. Formally, DMI is the sum of the final probe values after positive and negative probe responses have been assigned values of 1 or 0 , respectively.

The characteristics of the probes that were ultimately selected for inclusion in our PPHMCOVID-19 included: high response rates for COVID-19 samples, low response rates for control samples, and complementary recognition to maximize coverage across the COVID-19 positive samples (Fig. 1H and Table S3). Our initial assessment of the PPHMCOVID-19 was based on receiveroperating-characteristic (ROC) curves. The ability of PPHMCOVID-19 to discriminate between COVID-19 and control serum samples was significant $(P<0.001)$, with an area under the curve (AUC, i.e., the overall accuracy of the test) equal to 0.965 (95\% confidence interval, 0.95 to 0.98 ) (Fig. 1I). DMI $=2$ was chosen as the optimal cut-off value for the PPHM COVID-19 $_{\text {because it }}$ provided the lowest false negative and false positive rates, achieving $97.3 \%$ specificity and $92.4 \%$ sensitivity for the training group.

We simulated the impact of population variation on the cut-off value of DMI by testing random patient subgroups sampled within the training group, and found that although the response rates

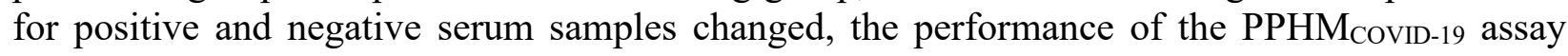
remained consistent (Table S4). We thus obtained a PPHMCOvID-19 comprising eight peptide 
probes and one whole protein-RBD probe, using a cut-off value of 10 for each individual probe and a cut-off value of 2 for DMI (i.e., the microarray level).

\section{Sampling time can confound the performance of serological assays}

To demonstrate how sampling time can confound the performance of serological assays, we re-

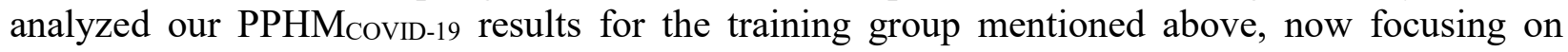
differences in IgG sero-dynamics between the peptides and RBD. Owing to complex immunological factors (e.g., differences in immunological history, genetic background, and other contributing factors) and/or potential differences in infection conditions (e.g., viral load), i) patients vary in their incubation periods (e.g., the median incubation period for COVID-19 is four days (18) (Fig. 2A, bottom left); ii) patients experience differences in the duration for each of their respective sero-status stage (Fig. 2A, middle). Thus, even for samples collected at an identical dpo point, cohort sera collected at any given date will contain samples from all three sero-status stages, resulting in different performance of PPHM $\mathrm{COVID-19}_{\text {(Fig. S3). }}$

Using longitudinal serum samples for 3 patients that we obtained in another ongoing collaboration (Patients a1, a2, and a3), we were able to demonstrate the impact of sampling time on both viral- and sero-status. We found that although two confirmed COVID-19 patients were sampled at the same date (Feb. $6^{\text {th }}$ ), Patient-al had a false negative because of sampling within his window period (i.e., sampling too early) (Fig. 2B). In contrast, Patient-a2/a3 tested positive because of prolonged sero-positive periods. This example of a window period false negative result detected for Patient-al provides the opportunity to show how this problem of false negatives acquired in the window period (i.e., sampling too early) can be resolved: via

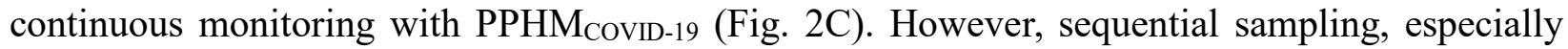
starting from early dpo, is difficult to achieve in practice, especially when considering that whole-protein-based methods require the capture of a four-fold increase in the IgG level in a follow-up test (11). Below, we show how these sampling-time-related problems can be resolved by advancing diagnostic technologies.

\section{Some peptides enter into the sero-positive period while RBD is still in its window period}

Notably, in the present study we found that some pathogen-derived peptides have potentially shorter window periods than whole proteins in the host, and thus allow for substantially earlier detection of infection (Fig. 2D, middle). For example, Patient-a2 showed positive test results at 9 dpo for three peptides (P-S15, P-S64, and P-S104), but did not show a positive result for RBD until $15 \mathrm{dpo}$, thus resulting in a positive diagnosis for COVID-19 by PPHM COVID-19 $_{\text {at }} 9$ dpo but a false negative diagnosis by CLIA (Fig. 2E).

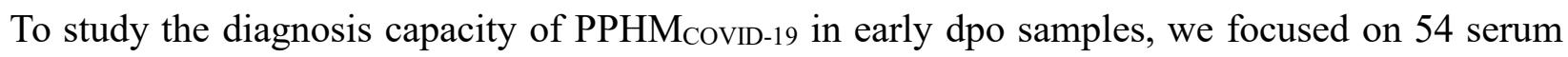
samples $($ dpo $\leq 10)$ of the 289 COVID-19 sera with positive PCR test results (Fig. 2F top). Of the 23 CLIA negative serum samples, 11(11/54, 20.4\%) were PPHMCovID-19 positive but RBD (used as a discrete ELSIA) negative (i.e., in agreement with CLIA test results), findings clearly underscoring the impressive early diagnosis ability of short peptides (Fig $2 \mathrm{~F}$ bottom left). Of the 31 positive serum samples from the CLIA analysis, 3(3/54, 5.6\%) were PPHM CoviD-19 positive but RBD negative (Fig 2F bottom right). It should be noted that the CLIA test results were all borderline positive (Table S5). Overall, the sensitivity achieved by PPHM COVID-19 $_{\text {and CLIA for }}$ these 54 serum samples with early dpo was $42(42 / 54,77.8 \%)$ and $31(31 / 54,57.4 \%)$, respectively. 
medRxiv preprint doi: https://doi.org/10.1101/2020.08.11.20172452; this version posted August 11, 2020. The copyright holder for this preprint (which was not certified by peer review) is the author/funder, who has granted medRxiv a license to display the preprint in perpetuity. All rights reserved. No reuse allowed without permission.

Note that we examined 12 serum samples from Figure 2F (in red) which were initially detected

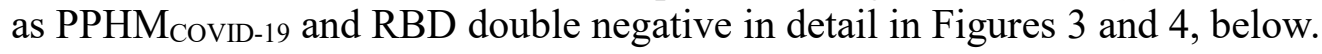

Some peptides remain in the sero-positive period even after RBD has entered into its seronegative period

A clear trend from our data is that the cohort samples were largely obtained from the prolonged sero-positive period: of the 80 patients who contributed sequential serum samples, 71 patients had all positive PPHM COVID-19 $_{\text {results }}(88.8 \%, 71 / 80)$ for serum samples collected from 1 to 77 dpo (Fig. 1B pink, Fig. S3).

Unexpectedly, we found that 7 serum samples (dpo $>10)$ exhibited positive PPHMCOVID-19 results while also yielding a negative RBD signal (Fig. 3A, red and Fig. S4). If these seven serum samples are not in the window period of RBD, such results indicate that pathogen-derived peptides apparently have a longer sero-positive period than RBD (Fig. S4). Moreover,

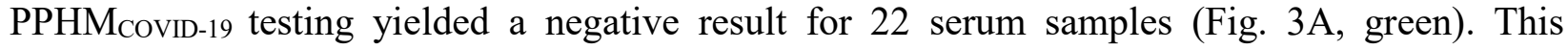
unusual early sero-reversion was further supported by the results obtained using the highsensitivity iteration of PPHM ${ }_{\mathrm{COVID}-19}$, which can detect IgG levels below the limit of detection for

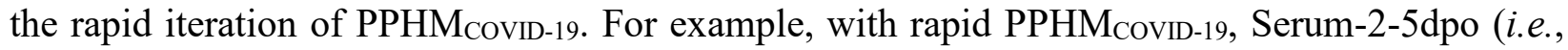
Serum-n-dpo, where $\mathrm{n}$ is the Patient-ID) tested positive but Serum-2-12dpo tested negative (Fig.

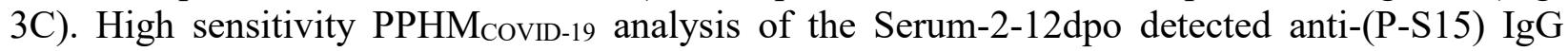
and anti-(P-S104) IgG, indicating a recent sero-reversion event (Fig. 3D). The ability of high-

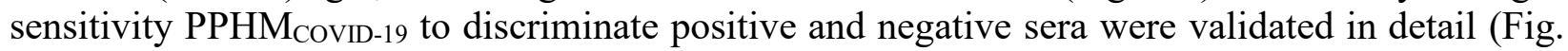
3C-E and Fig. S5). Thus, for analyzing these $29(7+22)$ serum samples with early sero-reversion, CLIA detected none $(0 / 29,0 \%)$, whereas the sensitivity of PPHMCOVID-19 was $24.1 \%(7 / 29)$.

\section{The 35 suspected subjects were all PPHMCOVID-19 positive and confirmed as COVID-19 patients}

To further explore the diagnosis capacity of PPHM CovID-19, we next examined the 35 suspected serum samples that were collected from 29 subjects, all of whom had an affirmative close contact history but were deemed negative based on both PCR and CLIA assays (Fig. 1A, bottom middle). Of these 29 subjects, 26 presented with COVID-19-like symptom whereas 3 did not (Fig 3F); however, these 3 asymptomatic subjects had radiology results indicating a positive COVID-19 status. Given their epidemiological histories and clinical features, now viewed in light of their

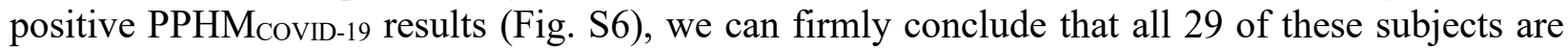
indeed COVID-19 cases. There were 3 subjects who had one positive and one negative PPHM $_{\text {COVID-19 }}$ result, indicating early sero-reversion (Fig. 3B, Patient-8/9/10). We also noted that Serum-16-5dpo was in the sero-positive period for peptide-based analysis but was in the window period for RBD (Fig. S6); Serum-12-28dpo was in the sero-positive period for peptides but the sero-negative period for RBD. Collectively, these results clearly highlight that PPHM COVID-19 has $_{1}$ overall higher sensitivity than whole-protein(RBD)-based assays (32/35 vs. 0/35). A total of 111 false negative PCR results was produced for these 29 patients, which could have been avoided if

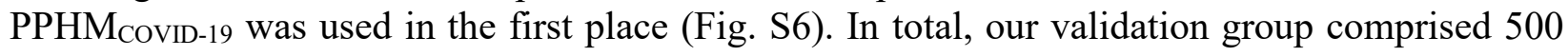
serum samples (Fig. 1A bottom) from 414 COVID-19 patients (Fig. 1B top, and Table S1). 
Of the 500 serum samples from 414 COVID-19 patients, we conducted a layered analysis for detection sensitivity according to four clinical classifications of COVID-19 (6). For asymptomatic, moderate and severe classifications, PPHMCOVID-19 showed superior performance over both whole-protein(RBD)- and PCR-based assays (Table 1 and Fig. S7); this superior performance was attributed to PPHM's ability to assess COVID-19 status outside of the typical detection time frames used with whole-protein(RBD)- and PCR-based assays. The "critical classification" population was too small to enable any definitive conclusions about performance. However, we speculate that PCR-based assays may actually have an advantage for this classification: critical disease status is typically associated with viral-presence and is thus easy to sample (i.e., less prone to false negative due to non-invasive sampling). The relatively low

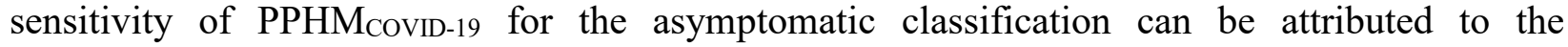
aforementioned "sampling too late" problem, especially for those patients exhibiting early seroreversion. This is also complicated by the different methods that were used to determine the dpo for the asymptomatic patients (Fig. S8). Nevertheless, our data support that PPHM COVID-19 $_{\text {can be }}$ universally applied for all four classifications of COVID-19.

Identification of a patient subgroup that exhibited early sero-reversion and is prone to false PPHMCOVID-19 negative results

We also conducted a detailed study of 25 mis-diagnosed samples (i.e., false negative

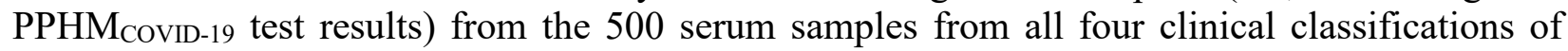
COVID-19, with a particular emphasis on patients having sequential serum samples. This analysis turned out to be an effective way of identifying low probability events. For example, Serum-7-2dpo showed a PPHM COvID-19 positive result by DMI (and was PCR positive), whereas Serum-7-6dpo was PPHM CovID-19 negative (and PCR negative) (Fig. 3B). We categorized Patient-7 into a patient subgroup characterized by early sero-reversion for the following reasons: i) medium to low anti-peptide IgG signal; ii) low DMI value; iii) short interval between viralpresence and absence, accompanied fast $\mathrm{IgG}$ elimination; iv) the basis used for dpo determination for asymptomatic patients (i.e., dpi could actually be much larger than dpo) (Fig. S8). Patient-8 from the asymptomatic class showed a similar trend, except that this subject was clinically confirmed as COVID-19 by a positive radiology result.

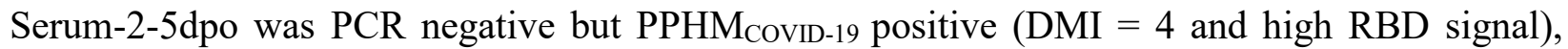

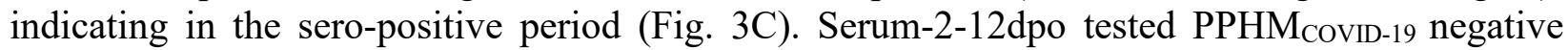
(both DMI and RBD), indicating that IgG had been eliminated within 7 days after viral clearance (Fig. 3B-D). Thus, Patient-2 was also categorized into the early sero-reversion patient subgroup. Overall, we identified a total of 22 serum samples from 20(20/414, 4.8\%) patients belonging to the early sero-reversion patient subgroup (Fig. 3B and Fig. S9). Note that a study of a larger early sero-reversion patient subgroup will be reported elsewhere.

This sub-group of patients characterized by early sero-reversion is apparently prone to false negative PPHM COVID-19 results; moreover, our detection of these patients motivated us to consider the testing-related-impacts of this and other types of low probability immunological events in considerable detail (see Discussion and Table S6). Very briefly, our theoretical analysis clearly indicated that low probability events will almost certainly have substantial problematic impacts on testing performed at the population level. Thus, we considered and accounted for the presence of such biological variation in the population as we developed our diagnostic decision- 
making protocol. That is, to avoid diagnosis failure caused by false negative or false positive PPHMCOvID-19 results, the Symptom (dpo)-Antibody-Nucleic acid-Epidemiological history (SANE) protocol we developed incorporates orthogonal data sources in discrete steps to overcome the accuracy-sabotaging impacts from these improbable (yet certain-to-be-encountered) biological conditions in the population.

There were three patients with paired PCR and serum samples tested who were PCR positive but PPHM $_{\text {COVID-19 }}$ negative. One serum sample (Serum-172-7dpo) was in her window period and was identified as COVID-19 patient by positive PCR test result (Fig. S10). The other two serum samples were from COVID-19 patients in the critical classification. Follow-up analysis exploring one sample (Serum-38-21dpo) revealed that although the rapid iteration PPHMCOvID-19 was negative, the high-sensitivity iteration PPHM COVID-19 result was positive (DMI $=2$ but negative RBD signal) (Fig. 3G bottom and Fig. S10). Considering both the relatively late dpo and the patient's condition (i.e., succumbing to late-stage stomach cancer 3 days), it is plausible that the

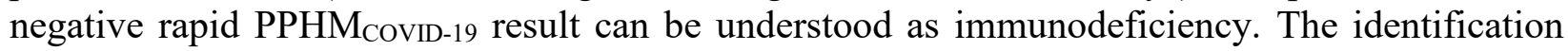
of 2 immunosuppressed patients whose serum samples yielded negative results for both CLIA and PPHM but a positive result from a PCR test strongly demonstrate the need for diagnostic protocols that incorporate orthogonal detection technologies.

Overall, these efforts identified a significant number of false negative results from single-use

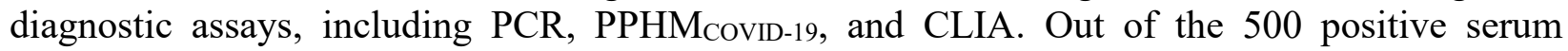
samples, PCR produced 18 false negative results that were attributed to sampling method, and between 159 to 370 false negative results that were attributed to sampling time (too late) (Fig. $3 \mathrm{G}$ top). Among the two serological assays, CLIA produced 13 while PPHM COVID-19 $_{\text {produced }}$ only 1 false negative result due to sampling time (too early); CLIA produced 55 while

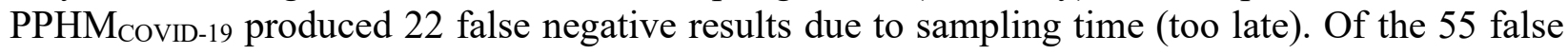
negative CLIA results due to sampling too late, 22 were false negatives from both PPHMCOVID-19 and CLIA, and 33 were PPHM COVID-19 positive but CLIA false negatives (Fig. 3G middle). This performance enhancement of PPHM COVID-19 over CLIA is substantial; indeed, as we show in Figure 4, this improvement enabled our development of SANE protocol that incorporates PPHM $_{\text {COVID-19 }}$ which has the potential to achieve full sensitivity and specificity for unambiguous COVID-19 diagnosis at the population level.

A negative RBD signal in PPHMCOVID-19 can be used to exclude false positive serum samples without close contact history

Among the 333 controls, we found that RBD showed a 98.8\% specificity (cut-off value $=10$ ) (Fig. 1D). Thus, we explored the use of an anti-RBD IgG negative result to help exclude PPHM $_{\text {COVID-19 }}$ false positives. COVID-19 patients will become RBD positive during a 14-day quarantine period. For example, Patient-40 exhibited RBD sero-conversion between 6 and 7 dpo

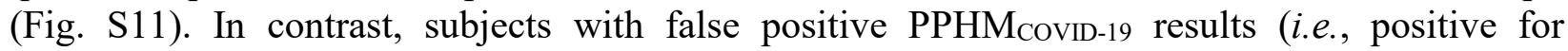
peptides but RBD negative) will remain RBD negative during the self-isolation period. There were 12 false positives in the 473 control samples (Fig. 1A bottom and Fig. S12).

In practice, it is essential that test results accurately confirm or refute COVID-19. Although we demonstrated above that sampling time related problems can be partially resolved by advancing

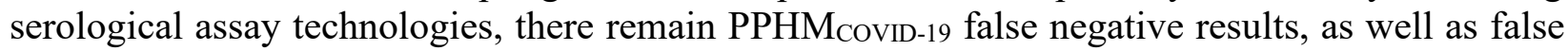
positive results (see Fig. 4). Thus, solutions beyond diagnostic technologies (including combined 
PPHM and PCR-based assays) such as diagnostic decision-making protocols that incorporate dpo/close contact history and other information are needed for efficient clinical practice, especially in cases of contradictory results. To visualize and apply these potential diagnostic outcomes in clinical practice, we developed a diagnostic decision-making protocol, i.e., Symptom-Antibody-Nucleic acid-Epidemiological history (SANE), including sub-protocol 1 (Fig. 4A) and sub-protocol 2 (Fig. 4B) for outpatients with and without COVID-19-like symptoms, respectively.

\section{Sub-protocol 1 of SANE for outpatients with COVID-19-like symptoms}

Seeking to mimic the real context of clinical practice, we reconstructed our validation group for

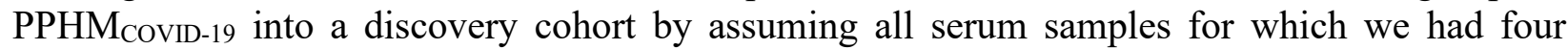
types of information (i.e., clinical symptoms, a PPHMCoviD-19 test result, a PCR test result, and an epidemiological history) were from different subjects; arranging the data in this way yielded 596 and 377 serum samples with and without COVID-19-like symptoms, respectively (Fig. 4).

Sub-protocol 1 of SANE was applied to process the 596 serum samples with COVID-19-like symptoms. There are three routes that can directly identify outpatients as COVID-19 patients (Fig. 4A, coordinate C2): i) the red route gives 390 outpatients with PPHM $\mathrm{COVID-19}$ and RBD

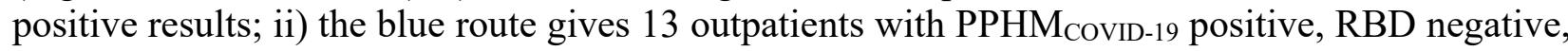
and PCR positive results; iii) the purple route gives 3 outpatients with PPHM COVID-19 negative but PCR positive results (Fig. S10). The total confirmation of COVID-19 is 406.

Note that two routes require continuous monitoring to deliver definitive diagnosis results (Fig.

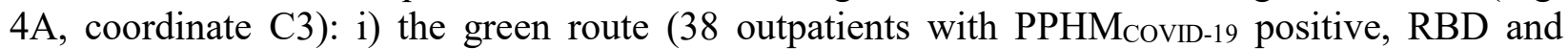

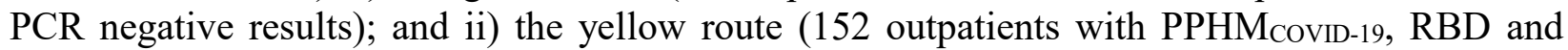
PCR all negative results). Thus, 190 outpatients in our study here require separate consideration because we did not have access to continuous monitoring data for them. Upon deployment of SANE, such patients would be assessed in their quarantine context based on the rapid iteration of PPHM COVID-19. Nevertheless, we were able to deduce from the data that we have that 23 outpatients should be understood as confirmed COVID-19: these 23 were identified when antiRBD IgGs in the window period for the first sampling and then show PPHM COVID-19 $_{\text {and RBD }}$ positive results. We also deduced that eight outpatients can be understood as confirmed false positive: because they will remain RBD negative (Fig. S12). We strongly suspect that 16 (Fig. 3B and Fig. S9) and seven (Fig. S4) outpatients actually belong to respectively the early seroreversion patient subgroup because of persistent negative PPHMCOVID-19 and RBD test results. The remaining 136 outpatients represent confirmed negative COVID-19 cases, and very likely have other etiologies (Fig. S13).

\section{Sub-protocol 2 of SANE for subjects without COVID-19-like symptoms}

Sub-protocol 2 of SANE was applied to the 377 serum samples from subjects without COVID19-like symptoms. Similar to sub-protocol 1, there are three routes that can directly identify outpatients as asymptomatic COVID-19 patients (Fig. 4C, coordinate H2): these red, blue, and purple routes give 32,8 , and 0 COVID-19 patients, respectively. The total number of confirmed COVID-19 cases based on these samples is 40. Considering that these outpatients are without COVID-like symptoms, upon testing negative with PPHM CovID-19 and RBD, their 
epidemiological history is used to determine whether a 6-day continuous monitoring (i.e., selfisolation or quarantine) is needed (Fig. 4C, coordinate $\mathrm{H} 2$ ). If the outpatient has a close contact history, similar to sub-protocol 1, there are two routes that require continuous monitoring to delivery definitive diagnose results (Fig. 4C, coordinate H3). Note that the brown route gives 325 outpatients without close contact history as negative for COVID-19 and yellow route gives 6 outpatients with close contact history need to be continuously monitored (Fig. 4C, coordinate H3). As in our presentation of sub-protocol 1, our present data did not enable full implementation of SANE for sub-protocol 2; however, in theory a total of 12 outpatients would

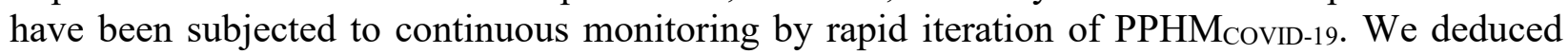
that four of these are apparently false positive because they have no COVID-19 like symptoms and will remain RBD negative. The six serum samples that were previously confirmed from early sero-reversion patient subgroup will be diagnosed as negative because of persistent negative PPHMCOVID-19 test results. Thus, the SANE protocol both overcomes the samplingmethod-related problems with PCR-based assays and carefully solves the aforementioned problems related to sampling time (too early or late) (Fig. S13).

\section{Discussion}

This study addressed a pressing issue that has to date limited the application of serological assays to clinical settings in the current fight against the global COVID-19 pandemic. Our study comprised two parts: the first being a validation of the PPHM platform (Fig. 1A) and the second being development of a diagnostic decision-making protocol (SANE) (Fig. 4). In addition to shining a light on some profound problems relating to the selection of cut-off values (see below), an emergent theme from the first part of our study is that currently deployed COVID-19 detection technologies are highly sensitive to factors which require correction. These include for example false negative samples resulting from sampling time issues (e.g., viral-absence, window period of IgG production, early sero-reversion, etc.) and sampling methods (e.g., non-invasive sampling) which do not actually reflect the known biology of SARS-CoV-2 replication. In the

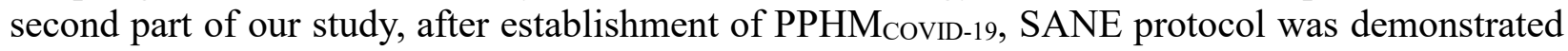
as a method which can fully resolve disease-state ambiguities resulting from testing based on a single diagnostic technology.

Ideally, the causal relationship between the detection of anti-protein IgGs and virus infection ensures that only the infected population will show a positive response to pathogen-derived protein probes in serological tests. However, due to many known factors such as heterophilic antibodies $(19,20)$ and high concentration of mAb $(17)$, this causal relationship can be masked by non-causal interactions (i.e., nonspecific interactions) so that a certain percentage of the noninfected population exhibit a positive anti-protein IgG signal. A cut-off value is thus needed to distinguish healthy and infected subjects (13). For example, in testing for SARS-CoV-2 infection, probe RBD showed $98.8 \%$ specificity whereas probe $\mathrm{N}$ protein showed only $73.0 \%$ specificity in this validation cohort $(5,10,16,21)$.

In contrast, PPHM defines cut-off values independent of probes in PPHM and the study population. The relationship between SARS-CoV-2 infection and anti-probe IgG response causally determines the probability of multiple probes being simultaneously positive, whereas negative results are determined by independent events (i.e., multiple non-specific interactions in one serum sample). Thus, we obtained a uniform cut-off value at 10 for individual probes and a 
universal cut-off value at 2 for DMI, as demonstrated in our previous papers for diagnosis of $P$. falciparum (22) and Peste des petits ruminants (14).

Our combined analysis of these multiple IsD curves motivated us to propose the following: that SARS-CoV-2 infection induces a humoral response characterized by i) anti-peptide IgGs appearing earlier than anti-RBD IgGs; ii) anti-peptide IgGs disappearing earlier than anti-RBD IgGs for most patients; iii) anti-peptide IgGs disappearing later than anti-RBD IgGs for a patient subgroup exhibiting early sero-reversion. Further, we suspect that the patient subgroup exhibiting early sero-reversion may be attributed to a "low dose" of SARS-CoV-2 infection. If so, perhaps this phenomenon could be detected in the low dose immunization cohort of various ongoing clinical trials for SARS-CoV-2 vaccine development $(7,8)$.

Despite the higher sensitivity and specificity available through serological testing as demonstrated in this paper and others $(10,23)$, PCR-based assays remain the most widely used diagnostic method for several reasons. For example, regardless of the exceptionally high false negative rate, false positives are exceedingly rare in PCR-based assays (9). Furthermore, false negative rates can be expected to be much lower in screening of the general population because the prevalence rate of SARS-CoV-2 is low in the general population. In contrast, serological tests may lead to both false negative and false positive results.

While potentially leading to epidemic viral spread (24), a high rate of false negative PCR results may be psychologically easier to manage in public health as compared to even a minimal number false positives, because they can potentially lead to unnecessary panic among the general population; these factors have resulted in the wide adoption of a less-reliable diagnostic method (25). Given the urgent need for diagnostic methods that provide $100 \%$ PPV or NPV, we hypothesized that improved serological assays could be used initially and then confirmed by PCR-based assays for COVID-19 diagnosis and screening of general populations through validation even in low prevalence areas.

Pursuing this, we designed and tested SANE protocol, to comprehensively address long-standing issues that plague serological testing and testing for SARS-CoV-2 infection, in particular. i) False negatives acquired by PCR-based assays; ii) false negatives generated in serological tests; and iii) false positives observed in serological test results. In this SANE protocol, PPHM is used first and supplemented by PCR because PPHM alone provides the highest sensitivity of all detection methods examined here (Table 1). Furthermore, our work also supports that the success of SANE depends on PPHM COVID-19 (Fig. S11). Highly notably, and suggesting the clinical and public health utility of our SANE protocol, performance assessments revealed that SANE achieves full PPV and NPV. We are unaware of any other COVID-19 testing protocols that achieve this fundamentally enabling level of diagnostic performance, and submit that SANE therefore warrants further examination for application in screening of the general population, even in low prevalence areas. Our ongoing work involves testing of 3000 sera from 3000 patients, and we are

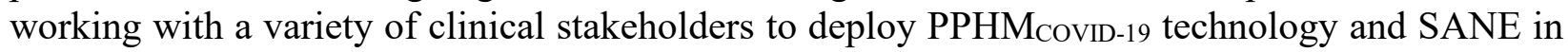
both biomedical research and public health.

There are several limitations in this study, mainly due to two unexpected discoveries: the fact that peptides may enter into the sero-positive period while RBD is still in its window period, and the aforementioned patient subgroup exhibiting early sero-reversion. The random selection process of serum samples resulted in a pool of primary latitudinal sera (i.e., cross-sectional sera), while longitudinal sera (ideally from clinical trials of vaccine development) is required to catch 
the sero-conversion and sero-reversion phases. Furthermore, we intend to obtain a significantly larger number of samples to further study the aforementioned small probability events (Table S6). Finally, a field study at a large scale is needed to examine whether the probe combination of

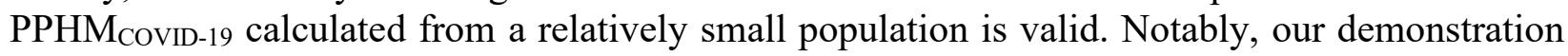
that sensitivity and specificity is population depended for whole-protein-based assays but not PPHM COVID-19 $_{\text {can }}$ be further confirmed with such work.

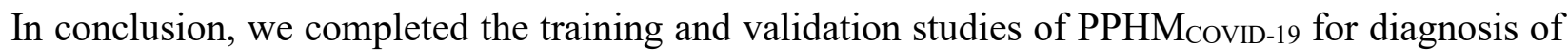
COVID-19. Given that PPHM has fixed cut-off values and that selection of apparently universal probes can be achieved with a small initial population, it is clear that PPHM development can be standardized, making it especially suitable for rapidly responding to sudden outbreaks of infectious diseases $(26,27)$. Moreover, the SANE protocol we demonstrate has the potential to significantly reduce the time required for quarantine for people with close contact history (i.e., from 14 days to 6 days). This PPHM platform is also able to provide a means of differentiating between infected and vaccinated hosts, which will be particularly useful during the development of a SARS-CoV-2 vaccine in the coming year.

\section{Materials and Methods}

Study design.

A total of 973 serum samples were collected in this study from Chinese Center for Disease Control and Prevention and six hospitals, The Central Hospital of Wuhan (WCH), The First Affiliated Hospital of Guangzhou Medical University (FAH), The 2nd People's Hospital of Shenzhen (SPH), Shenzhen Children's Hospital (SCH), Jinling Hospital (JL) and Huoshenshan Hospital (HSS) respectively. Among them, 463 sera from 384 patients with COVID-19 symptoms (Table S1), and 55 sera from 48 patients without COVID-19 symptoms. 122 sera of hospital inpatients due to other diseases and 333 anonymous serum collected before 2019, of which 133 serum samples were from patients with influenza or systemic lupus erythematosus.

A total 518 serum samples of 432 patients were enrolled from two designated hospitals, WCH (415) and FAH (17). Among them, 80 patients from WCH had sequential serum samples. The median age of 432 enrolled patients was 60 years (IQR, 47 - 69 years) and $54.8 \%$ were females. Among them, 306 serum samples from 246 patients positive for SARS-CoV-2 with PCR on nasal and pharyngeal swab specimens, and another 159 serum samples from 139 patients were confirmed to be infected with SARS-CoV-2 by serological test according to the Guidelines of the Diagnosis and Treatment of New Coronavirus Pneumonia published by the National Health Commission of China ( 6 ).

Another 53 serum samples from 47 patients suspected to have COVID-19 but negative for SARS-CoV-2 with PCR for at least two sequential tests. Among them, 26 patients with suspected COVI-19 admitted to WCH with COVID-19 symptoms, and 3 close contacts (patients' family member) without COVID-19 symptoms but abnormal pulmonary imaging.

The study was approved by the ethics committee of the four hospitals mentioned above (Medical Research Ethics No. 44, 2020). Written informed consent was waived in light of this emerging infectious disease of high clinical relevance. All healthy control subjects signed written informed consent prior to the collection of peripheral blood. 
medRxiv preprint doi: https://doi.org/10.1101/2020.08.11.20172452; this version posted August 11, 2020. The copyright holder for this preprint (which was not certified by peer review) is the author/funder, who has granted medRxiv a license to display the preprint in perpetuity.

\section{Serological assays for SARS-CoV-2.}

All serum samples were inactivated at $56^{\circ} \mathrm{C}$ for $30 \mathrm{~min}$ and stored at $-20{ }^{\circ} \mathrm{C}$ before testing. There are two serological assays in this study, single probe chemiluminescence assay (CLIA) and multi-probe PPHM assay.

Single probe CLIA was conducted on an Axceed 260 automatic CLIA analyzer (Bioscience (Tianjin) Co., Ltd.). The cut-off values of IgM and IgG are 53292 and 73400, respectively. The relative luminescence value (RLV) greater than or equal to 1.0 is positive for specific $\operatorname{IgM}$ and IgG.

Peptide-protein hybrid microarray (PPHM) included eight peptides and one whole protein (RBD) (GenScript, Jiangsu, China). Multi-probe PPHMCOVID-19 assay was conducted as previously described. Briefly, serum was first diluted 1:100 with serum-dilution buffer, then $100 \mu \mathrm{L}$ diluted sample was added into each microarray well and incubated for $30 \mathrm{~min}$ or 2 hours on a shaker $\left(500 \mathrm{rpm}, 37^{\circ} \mathrm{C}\right)$. Then, the microarray incubated with horseradish peroxidase conjugated goat anti-human IgG (ZSGB-BIO, Beijing, China) for another $30 \mathrm{~min}$ on a shaker $\left(500 \mathrm{rpm}, 37^{\circ} \mathrm{C}\right)$. Finally, 1-step Ultra TMB-Blotting Solution (Thermo Scientific, USA) was used to detect the informative signal of IgGs against probes using microarray imager, which was then analyzed using the imager accompanied commercial software (Suzhou Epitope, Suzhou, China). The cutoff value of each probe is 10. Any two or more probes in PPHM COVID-19 whose signals are higher than 10 are confirmed as positive samples.

\section{$\underline{\text { Statistical analysis }}$}

The Fisher's exact test was performed to identify statistically significant probes between negative and COVID-19 sera with a p-value cutoff of 0.05 . Then the PPHM COVID-19 which contained eight peptides and one protein-RBD were calculated for combined diagnostic performance by an in-house script. The $95 \%$ CI of the sensitivity and specificity were calculated from binomial probabilities using adjusted Wald method. ROC was performed using R package "pROC". 
medRxiv preprint doi: https://doi.org/10.1101/2020.08.11.20172452; this version posted August 11, 2020. The copyright holder for this preprint (which was not certified by peer review) is the author/funder, who has granted medRxiv a license to display the preprint in perpetuity. All rights reserved. No reuse allowed without permission.

\section{References and Notes:}

1. S. M. Kissler, C. Tedijanto, E. Goldstein, Y. H. Grad, M. Lipsitch, Projecting the transmission dynamics of SARS-CoV-2 through the post-pandemic period. Science, (2020). doi: $10.1126 /$ science.abb5793

2. J. D. Silverman, N. Hupert, A. D. Washburne, Using influenza surveillance networks to estimate state-specific prevalence of SARS-CoV-2 in the United States. Sci Transl Med 12, (2020). doi: 10.1126/scitranslmed.abc1126

3. L. Zou et al., SARS-CoV-2 Viral Load in Upper Respiratory Specimens of Infected Patients. $N$ Engl J Med 382, 1177-1179 (2020).

4. W. Wang et al., Detection of SARS-CoV-2 in Different Types of Clinical Specimens. JAMA, (2020). doi: 10.1001/jama.2020.3786

5. Q. X. Long et al., Antibody responses to SARS-CoV-2 in patients with COVID-19. Nat Med 26, 845-848 (2020).

6. Chinese Clinical Guidance for COVID-19 Pneumonia Diagnosis and Treatment, 7th edition (National Health Commission of the People's Rupublic of China, 2020).

7. F.-C. Zhu et al., Safety, tolerability, and immunogenicity of a recombinant adenovirus type-5 vectored COVID-19 vaccine: a dose-escalation, open-label, non-randomised, first-in-human trial. The Lancet 395, 1845-1854 (2020).

8. H. Wang et al., Development of an Inactivated Vaccine Candidate, BBIBP-CorV, with Potent Protection against SARS-CoV-2. Cell, (2020). doi: 10.1016/j.cell.2020.06.008

9. R. D. Kirkcaldy, B. A. King, J. T. Brooks, COVID-19 and Postinfection Immunity: Limited Evidence, Many Remaining Questions. JAMA, (2020). doi: 10.1001/jama.2020.7869

10. K. K.-W. To et al., Seroprevalence of SARS-CoV-2 in Hong Kong and in residents evacuated from Hubei province, China: a multicohort study. The Lancet Microbe 1, e111e118 (2020).

11. X. Xu et al., Seroprevalence of immunoglobulin $\mathrm{M}$ and $\mathrm{G}$ antibodies against SARS-CoV-2 in China. Nat Med, (2020). doi: 10.1038/s41591-020-0949-6

12. V. J. Munster, M. Koopmans, N. van Doremalen, D. van Riel, E. de Wit, A Novel Coronavirus Emerging in China - Key Questions for Impact Assessment. $N$ Engl J Med 382, 692-694 (2020).

13. A. G. Lalkhen, A. McCluskey, Clinical tests: sensitivity and specificity. Continuing Education in Anaesthesia Critical Care \& Pain 8, 221-223 (2008).

14. Q. Xue et al., Epitope-Containing Short Peptides Capture Distinct IgG Serodynamics That Enable Differentiating Infected from Vaccinated Animals for Live-Attenuated Vaccines. $J$ Virol 94, (2020).

15. Z. Li et al., Development and clinical application of a rapid IgM-IgG combined antibody test for SARS-CoV-2 infection diagnosis. J Med Virol, (2020). doi: 10.1002/jmv.25727

16. L. Guo et al., Profiling Early Humoral Response to Diagnose Novel Coronavirus Disease (COVID-19). Clin Infect Dis, (2020). doi: 10.1093/cid/ciaa310

17. M. Huang, Q. Ma, X. Liu, B. Li, H. Ma, Initiator Integrated Poly(dimethysiloxane)-Based Microarray as a Tool for Revealing the Relationship between Nonspecific Interactions and Irreproducibility. Anal Chem 87, 7085-7091 (2015).

18. W. J. Guan et al., Clinical Characteristics of Coronavirus Disease 2019 in China. $N$ Engl J Med 382, 1708-1720 (2020). 
medRxiv preprint doi: https://doi.org/10.1101/2020.08.11.20172452; this version posted August 11, 2020. The copyright holder for this preprint (which was not certified by peer review) is the author/funder, who has granted medRxiv a license to display the preprint in perpetuity.

19. G. Lippi, R. Aloe, T. Meschi, L. Borghi, G. Cervellin, Interference from heterophilic antibodies in troponin testing. Case report and systematic review of the literature. Clin Chim Acta 426, 79-84 (2013).

20. A. N. Sontakke, R. S. Tare, A duality in the roles of reactive oxygen species with respect to bone metabolism. Clinica Chimica Acta 318, 145-148 (2002).

21. Y. Yamaoka et al., Whole nucleocapsid protein of SARS-CoV-2 may cause false positive results in serological assays. Clin Infect Dis, (2020). doi: 10.1093/cid/ciaa637/5843448

22. Y. Lu et al., Chimeric peptide constructs comprising linear B-cell epitopes: application to the serodiagnosis of infectious diseases. Sci Rep 5, 13364 (2015).

23. Q. X. Long et al., Clinical and immunological assessment of asymptomatic SARS-CoV-2 infections. Nat Med, (2020). doi: 10.1038/s41591-020-0965-6

24. X. He et al., Temporal dynamics in viral shedding and transmissibility of COVID-19. Nat Med 26, 672-675 (2020).

25. N. Sethuraman, S. S. Jeremiah, A. Ryo, Interpreting Diagnostic Tests for SARS-CoV-2. JAMA, (2020). doi: 10.1001/jama.2020.8259

26. G. F. Gao, From "A"IV to "Z”'IKV: Attacks from Emerging and Re-emerging Pathogens. Cell 172, 1157-1159 (2018).

27. D. Carroll et al., The Global Virome Project. Science 359, 872-874 (2018).

Acknowledgments: This study was supported by Zhejiang University special scientific research fund for COVID-19 prevention and control (2020XGZX001 to N.Z., 2020XGZX025 to B.S., 2020XGZX040 to H.M.), China Evergrande Group (2020GIRHHMS04 to B.S. and H.M.) and Self-funded project of SINANO, CAS (E051020101 to H.M.).

Author contributions H.M., N.Z., B.S., and H.W. conceived the study; H.C., P.Z., D.G., S.H., D.M., R.W., J.H., Z.L., S.W., C.L. and X.X. performed all the experiments; H.C., Y.L., Y.D., and L.Y. analyzed the results; H.C., Y.L., W.X. and H.M. wrote the manuscript. All authors contributed to the revision and review of the manuscript.

Competing interests: The authors declare no competing financial interests.

Data and materials availability: All data associated with this study are in the main text or Supplementary Materials. 


\section{Figures}

A

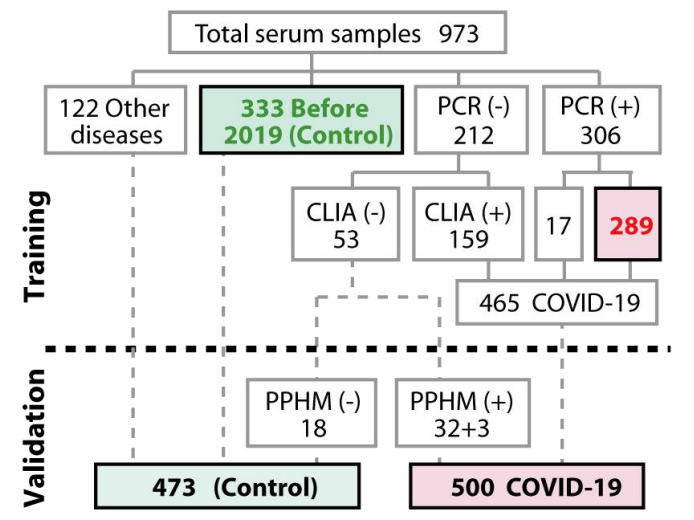

B

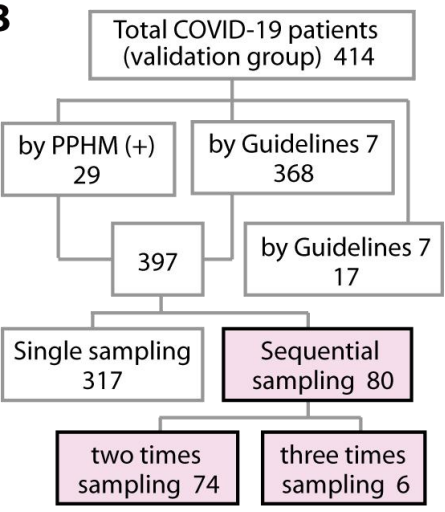

C
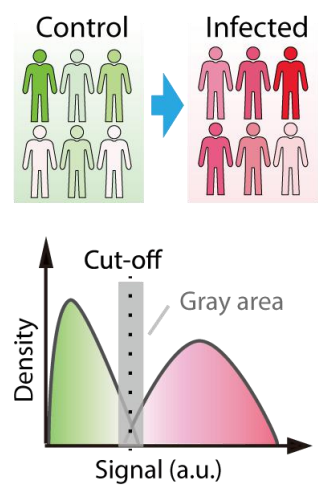

D

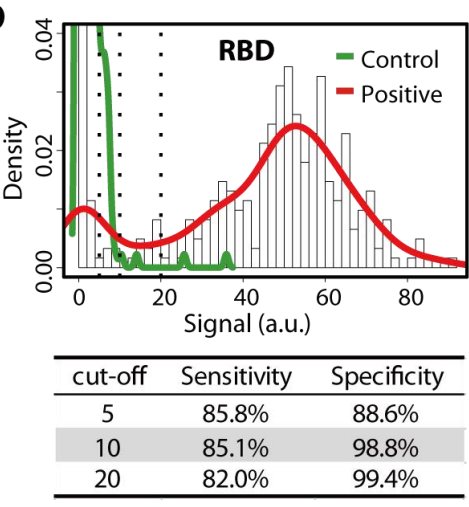

G

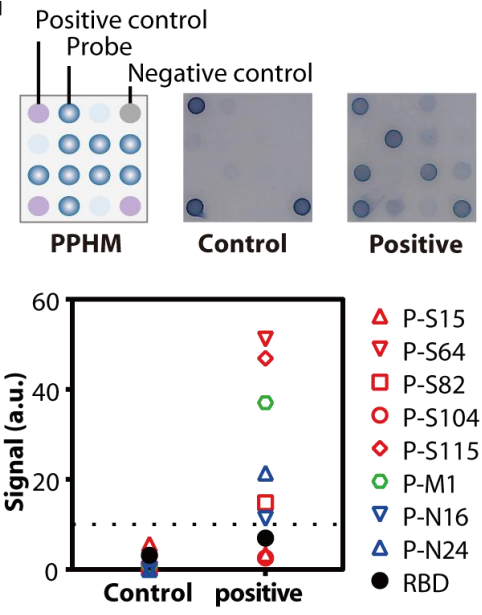

$\mathbf{E}$

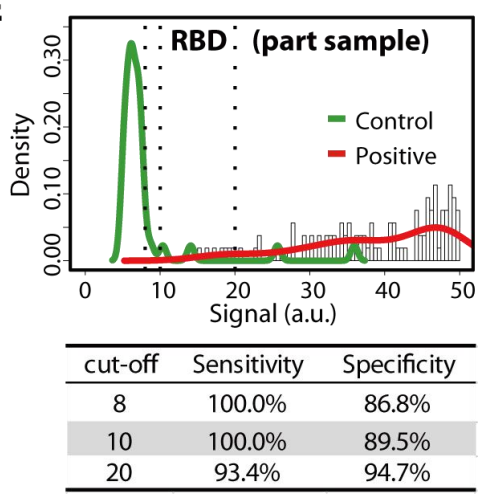

H

\begin{tabular}{ccc}
\hline $\begin{array}{c}\text { Response } \\
\text { rate }\end{array}$ & Positive & Control \\
\hline P-S15 & $35.6 \%$ & $2.7 \%$ \\
P-S64 & $63.0 \%$ & $2.1 \%$ \\
P-S82 & $56.1 \%$ & $4.8 \%$ \\
P-S104 & $45.3 \%$ & $4.5 \%$ \\
P-S115 & $66.8 \%$ & $0.6 \%$ \\
P-M1 & $38.4 \%$ & $0.3 \%$ \\
\hline P-N16 & $49.1 \%$ & $4.5 \%$ \\
\hline P-N24 & $47.4 \%$ & $2.7 \%$ \\
RBD & $85.1 \%$ & $1.2 \%$ \\
\hline NProtein & $94.8 \%$ & $27.0 \%$ \\
\hline & & \\
\hline Cut-off & Sensitivity & Specificity \\
\hline DMl $\geqslant 1$ & $94.5 \%$ & $79.6 \%$ \\
DMl $\geqslant 2$ & $92.4 \%$ & $97.3 \%$ \\
\hline DMl $\geqslant 3$ & $86.9 \%$ & $99.7 \%$ \\
\hline
\end{tabular}

$\mathbf{F}$

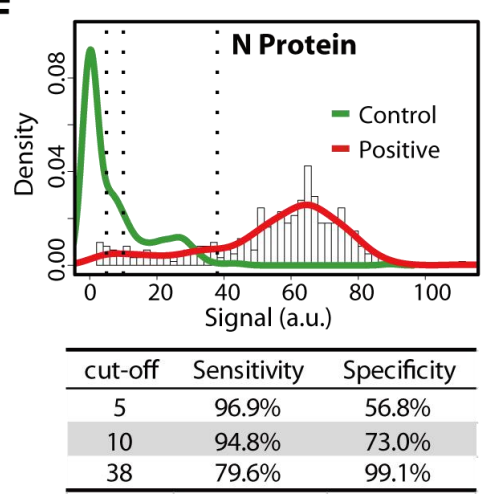

I

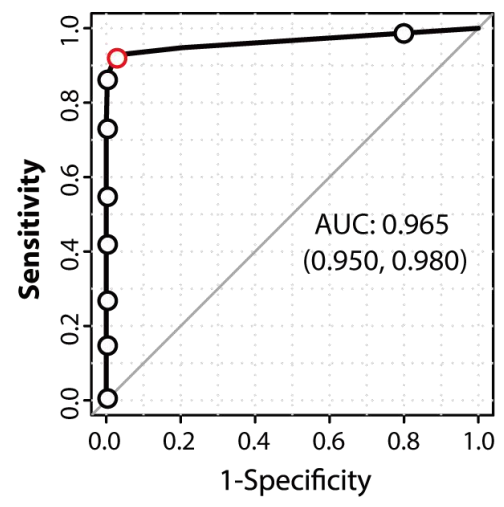

Fig. 1. Impact of cut-off value and population on the sensitivity and specificity of wholeprotein-based and PPHM assays. To demonstrate how determination of cut-off values can negatively impact sensitivity and specificity, we screened PPHMCovID-19 against a training group of 333 control and 289 COVID-19 positive serum samples. (A)-(B) Workflow for serum samples and patients. The initial disease status classification is performed prior to PPHM COVID-19. $_{\text {(C) }}$ Schematic illustration of whole-protein-based assays to determine cut-off values using the gray area at the overlapping interface of positive and negative test results. Since the microarray can be 
medRxiv preprint doi: https://doi.org/10.1101/2020.08.11.20172452; this version posted August 11, 2020. The copyright holder for this preprint (which was not certified by peer review) is the author/funder, who has granted medRxiv a license to display the preprint in perpetuity.

All rights reserved. No reuse allowed without permission.

used in a full PPHM configuration or as discrete ELISA probes, we used RBD and N protein in a PPHM as discrete ELISA probes for the comparison between anti-RBD IgG signals for the training group (D) and for a patient subgroup (E) comprised of 38 control and 106 COVID-19 sera, which demonstrated that variation in the population used for assay development can obviously affect test performance evaluation outcomes. (F) Results for anti-(N protein) IgG. (G) Schematic illustration of the layout of PPHM COVID-19 (eight peptides as probes as well was the RBD protein) (top left), representative images of negative (top middle) and positive sera (top right), and signals of individual probes in PPHM COVID-19 $_{10}$ for negative and positive serum samples (bottom). (H) Response rates for the $\mathrm{N}$ protein and for the probe molecules used in PPHM CoviD-

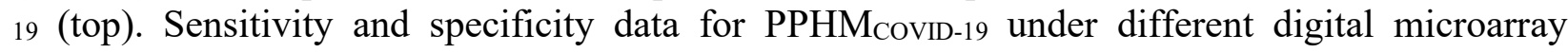
index (DMI) values (i.e., different cut-off values) (bottom). (I) A receiver-operatingcharacteristic (ROC) curve of PPHMCOvID-19. From right top to left bottom, DMI varies from 1 to 9 , with the red circle indicating DMI $=2$. The 0.965 AUC value indicated that PPHM is an outstanding serological test kit for COVID-19. The dashed lines indicate the cut-off values, including the arbitrary values selected by the assay developer, as well as the data-driven ones used for our PPHM assay. 
A

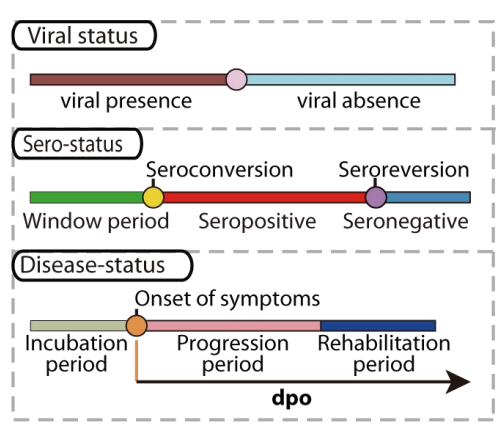

B

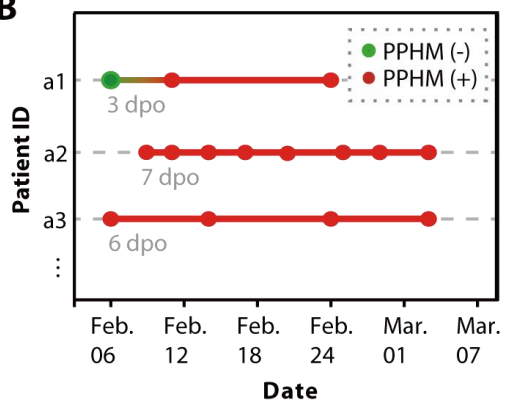

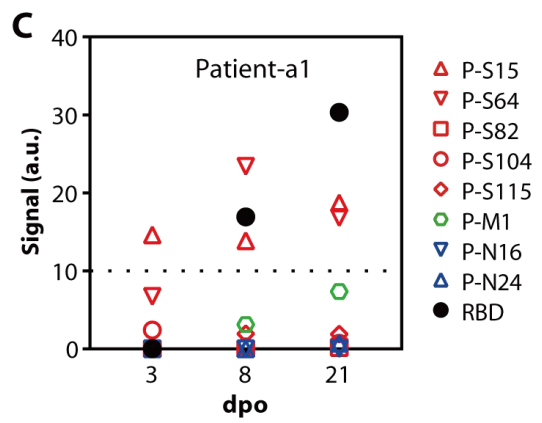
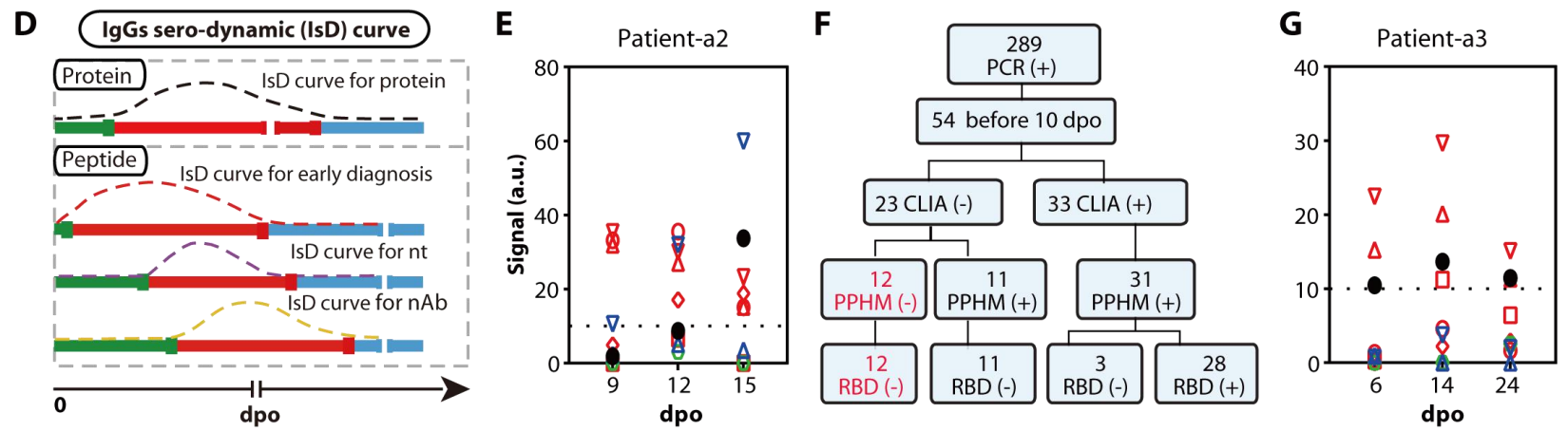

Fig. 2. Well-known early sampling limitations can be overcome by PPHM. (A) Variation among hosts in the incubation period and throughout each sero-status stage precludes reliable confirmation of viral infection status in the sero-positive stage (red). That is, serum sampling can result in false negatives if a sample is collected during an unsuitable sero-status stage within the window period (green), especially for cross-sectional sera. (B) Representative clinically confirmed COVID-19 patients exhibiting the type of ambiguous results described in A. (C) Detailed signal values of nine PPHM probes for Patient-al from B. (D) Distinct IgG serodynamic (IsD) curves for peptides vs. whole protein data. At each day post onset (dpo), IsD for whole protein (top) yields only one signal during the entire sero-positive period, whereas PPHM has multiple IsD curves, therefore providing rich information about the duration of each serostatus period. Some peptide probes are detectable during the anti-whole protein IgG window period, and thus allow earlier detection of infection (middle). Some peptides can mirror PCRbased assays (second bottom), and others provide a direct measure of patient capacity for viral clearance (bottom). (E) Signals of each PPHM probe at different dpo for Patient-a2, an example case of early detection from D. (F) Workflow for 54 serum samples with early dpo according

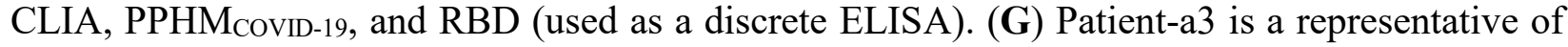
the highest frequency sample type, i.e., positive for COVID-19 at all three sampling points throughout the sero-positive period. 
A

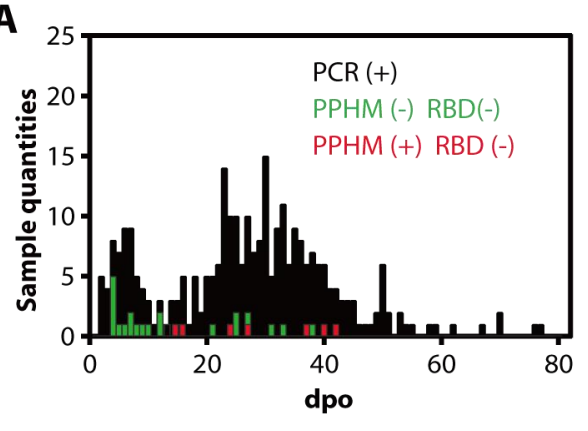

B

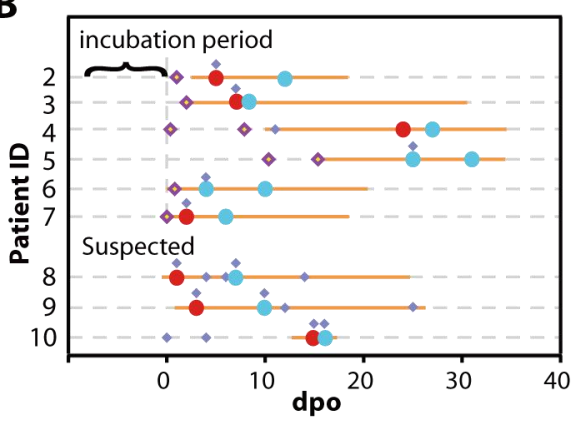

E

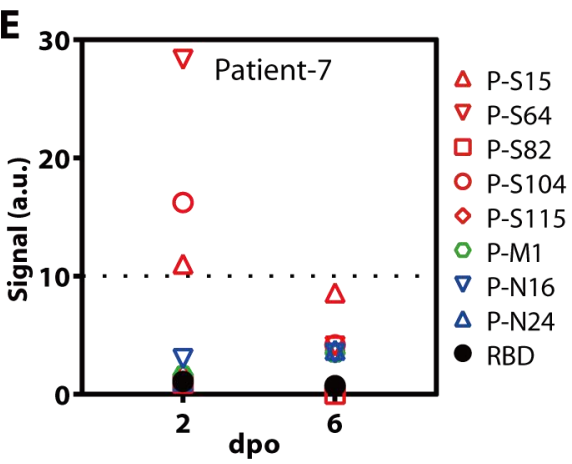

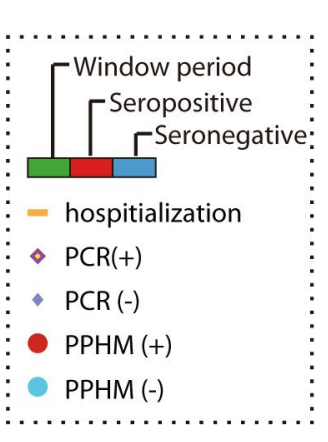

$\mathbf{F}$

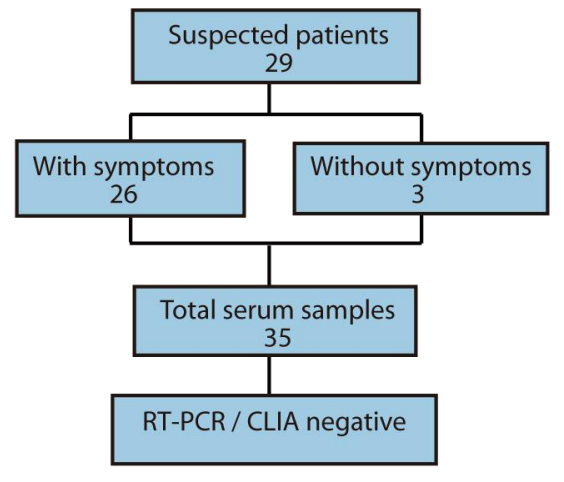

D
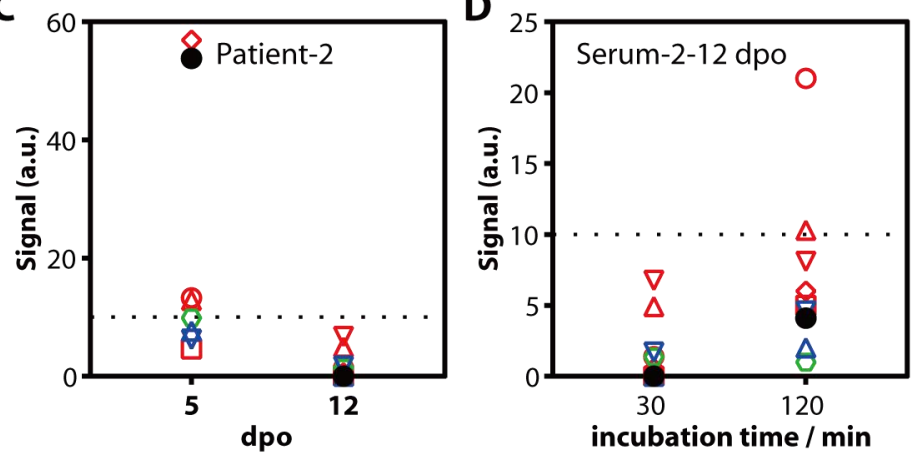

\section{G}

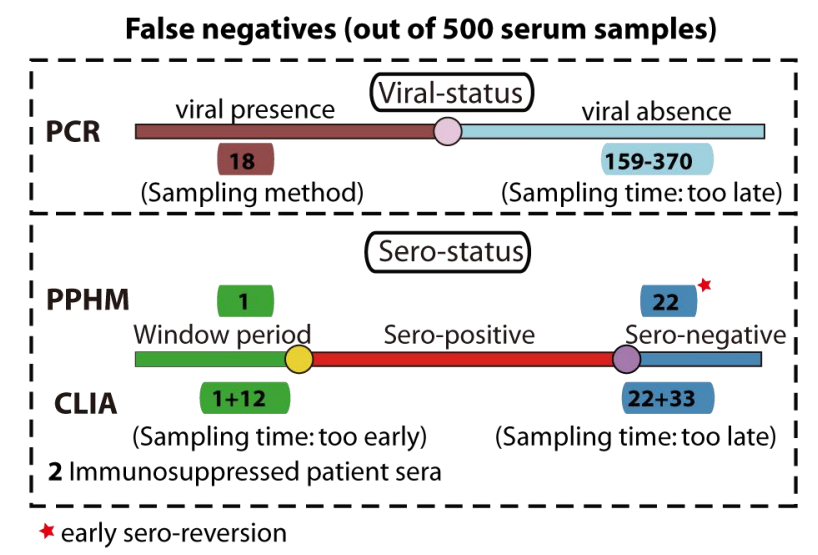

Fig. 3. Unexpected late sampling limitations can be overcome by PPHMcovid-19. (A) Distribution of 289 PCR positive serum samples of the training group against dpo; seven serum samples were PPHM COVID-19 positive but RBD negative (red) and 22 serum samples were PPHMcovid-19 negative (green). (B) PPHMCovID-19 assay results and dpo together identified a sub-group with unusually fast antibody clearance (i.e., early sero-reversion). (C) Patient-2 underwent sero-reversion between 5 and 12 dpo. (D) When using the high-sensitivity iteration of

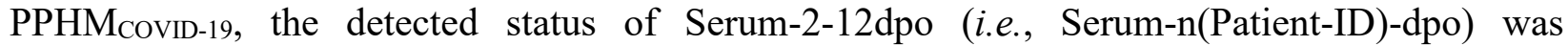
converted from negative to positive, resulting in a DMI change from 0 to 2, i.e., positive of COVID-19. (E) Asymptomatic Patient-7 underwent sero-reversion between 2 and 6 dpo. The dashed line indicates cut-off value. (F) Workflow of 29 suspected patients, all the 35 serum samples were tested PPHM COVID-19 $_{\text {positive. }}(\mathbf{G})$ All the false negative results of PCR, PPHM and CLIA caused by sampling method (e.g., non-invasive sampling) and sampling time (too early or late). 
A

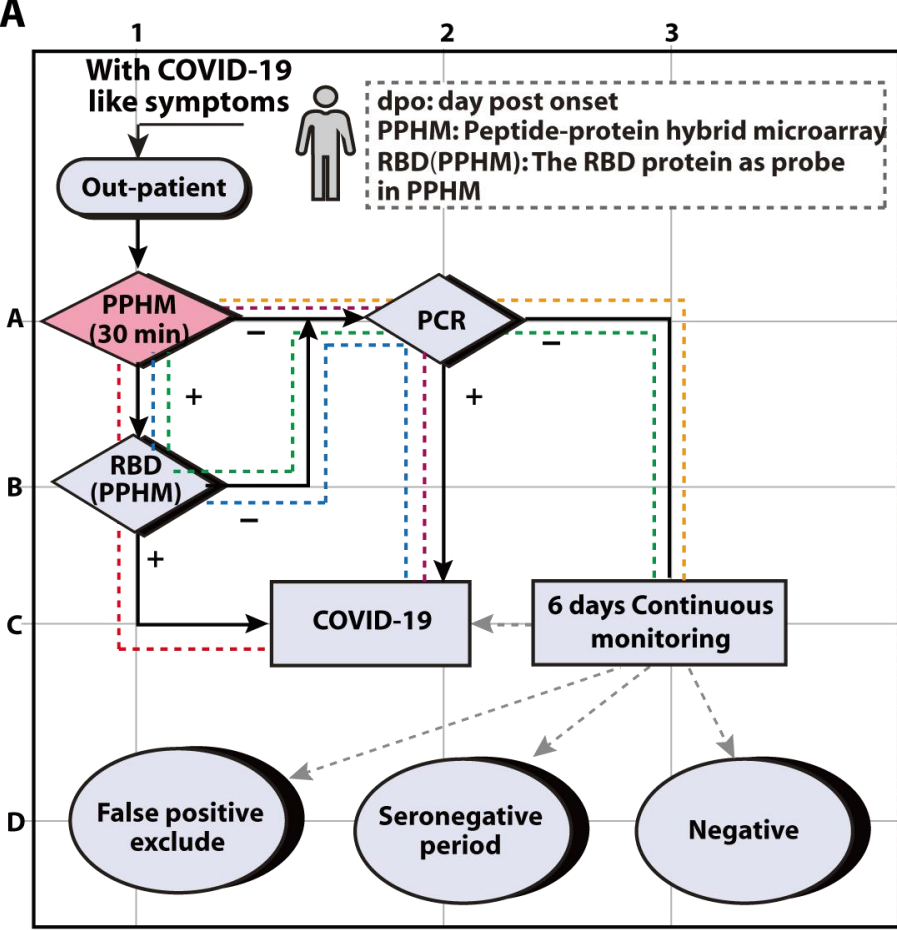

C

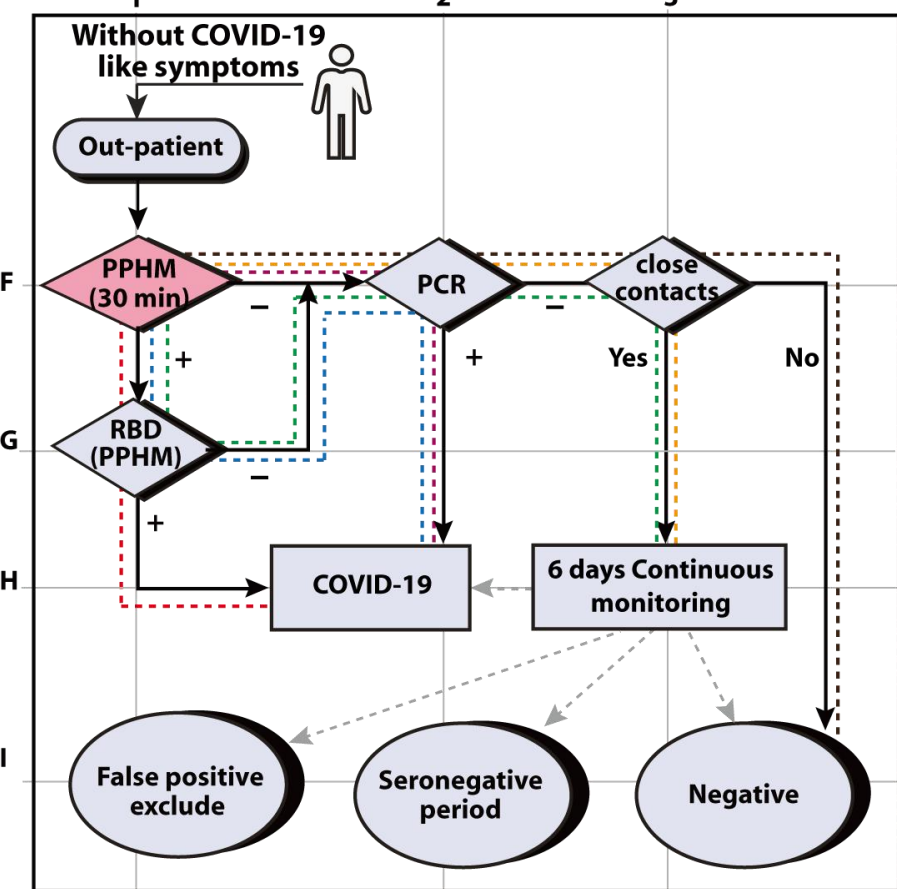

B

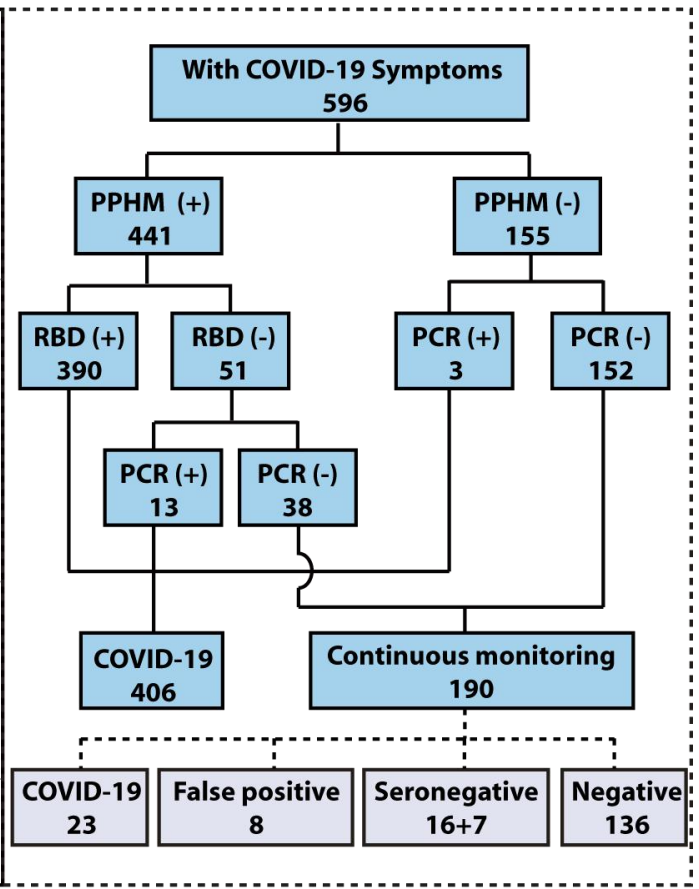

D

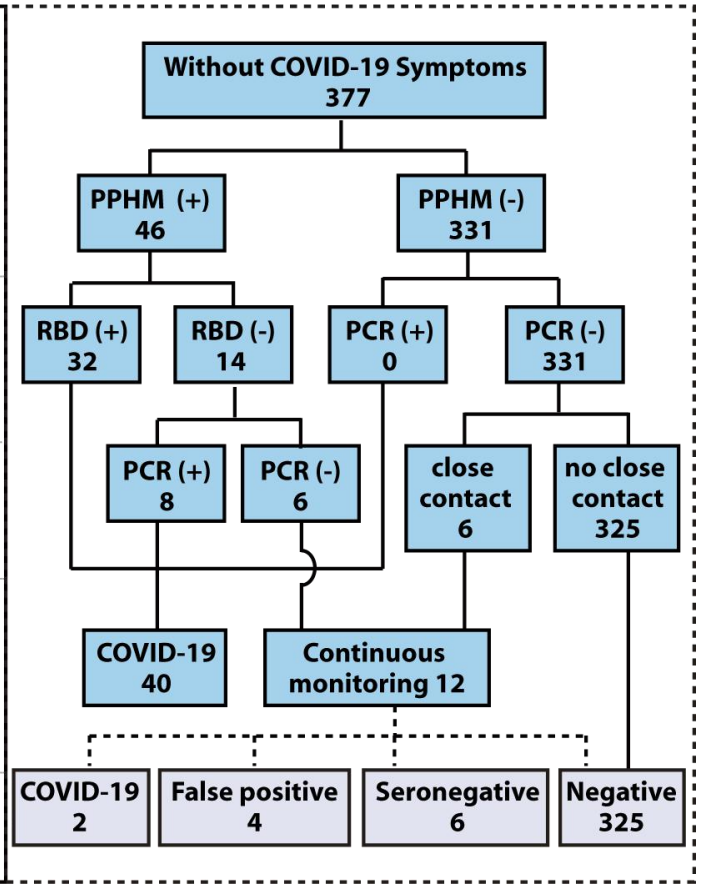

Fig. 4. A proposed diagnostic decision-making protocol (SANE) for outpatients with and without COVID-19-like symptoms. Efficient clinical practice can be achieved by combining the merits of multiple assay types in diagnostic decision-making protocols (here, complete sensitivity and specificity for outpatients with COVID-19-like symptoms). (A) Patients with COVID-19-like symptoms are sorted and processed through one of five routes in sub-protocol 1. All start with a rapid iteration of PPHMCOVID-19 assessment (grid A1) with subsequent PCR tests. 
medRxiv preprint doi: https://doi.org/10.1101/2020.08.11.20172452; this version posted August 11, 2020. The copyright holder for this preprint (which was not certified by peer review) is the author/funder, who has granted medRxiv a license to display the preprint in perpetuity.

All rights reserved. No reuse allowed without permission.

The primary confirmation of SARS-CoV-2 infection is a positive result by either or both PPHM

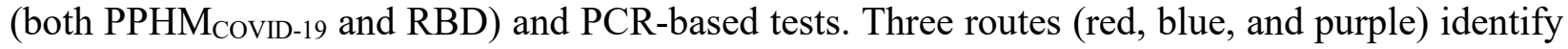
positive samples (grid $\mathrm{C} 2$ ). The green and yellow routes accommodate samples which require

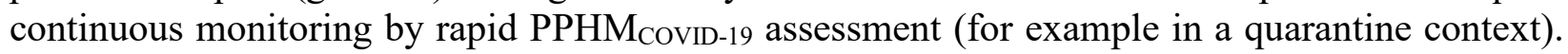
(B) Workflow of outpatients. (C) Outpatients without COVID-19-like symptoms are assessed through one of six routes in sub-protocol 2. The flow is similar to sub-protocol 1 except, when

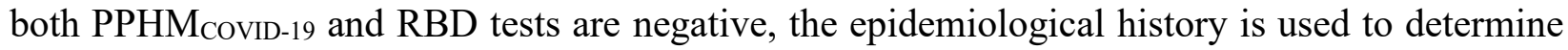
whether a 6-day continuous monitoring (i.e., quarantine) is needed (grid C2) for these outpatients lacking obvious COVID-like-symptoms. (D) Workflow of outpatients. 
medRxiv preprint doi: https://doi.org/10.1101/2020.08.11.20172452; this version posted August 11, 2020. The copyright holder for this preprint (which was not certified by peer review) is the author/funder, who has granted medRxiv a license to display the preprint in perpetuity.

All rights reserved. No reuse allowed without permission.

Table 1. Performance comparison among three diagnostic assays for all four clinical classifications of COVID-19.

\begin{tabular}{cccccccc}
\hline \multirow{2}{*}{ Classification } & \multirow{2}{*}{$\begin{array}{c}\text { Total } \\
\text { samples }\end{array}$} & \multicolumn{2}{c}{ PPHM } & \multicolumn{2}{c}{ RBD $^{\mathbf{a}}$} & \multicolumn{2}{c}{ PCR } \\
\cline { 3 - 8 } & & Positive & Sensitivity & Positive & Sensitivity & Positive & Sensitivity \\
\hline Asymptomatic & 48 & 42 & $87.5 \%$ & 31 & $64.6 \%$ & 34 & $70.8 \%$ \\
Moderate & 397 & 381 & $96.0 \%$ & 341 & $85.9 \%$ & 227 & $57.2 \%$ \\
Severe & 49 & 47 & $95.9 \%$ & 44 & $89.8 \%$ & 39 & $79.6 \%$ \\
Critical & 6 & 5 & $83.3 \%$ & 2 & $33.3 \%$ & 6 & $100.0 \%$ \\
Total & 500 & 475 & $95.0 \%$ & 418 & $83.6 \%$ & 306 & $61.2 \%$ \\
\hline
\end{tabular}

${ }^{\text {a }}$ RBD protein in PPHM as discrete ELISA probe. 


\section{Supplementary Materials for}

\section{A diagnostic decision-making protocol combines a new-generation of serological assay and PCR to fully resolve ambiguity in COVID-19 diagnosis}

Authors: Hu Cheng ${ }^{1,9} \uparrow$, Hao Chen ${ }^{2} \uparrow$, Yiting $\mathrm{Li}^{1} \uparrow$, Peiyan Zheng ${ }^{2}$, Dayong $\mathrm{Gu}^{3}$, Shiping $\mathrm{He}^{3}$, Dongli $\mathrm{Ma}^{4}$, Ruifang Wang ${ }^{5}$, Jun Han ${ }^{5}$, Zhongxin $\mathrm{Lu}^{6}$, Xinyi Xia ${ }^{7,8}$, Yi Deng ${ }^{1,9}$, Lan Yang ${ }^{1}$, Wenwen $\mathrm{Xu}^{1}$, Shanhui $\mathrm{Wu}^{2}$, Cuiying Liang ${ }^{2}$, Hui Wang ${ }^{6 *}$, Baoqing Sun ${ }^{2 *}$, Nanshan Zhong ${ }^{2 *}$, and Hongwei $\mathrm{Ma}^{1 *}$

\section{Affiliations:}

${ }^{1}$ Division of Nanobiomedicine, Suzhou Institute of Nano-Tech and Nano-Bionics, Chinese Academy of Sciences, Suzhou, 215123, China.

${ }^{2}$ Department of Allergy and Clinical Immunology, Guangzhou Institute of Respiratory Health, State Key Laboratory of Respiratory Disease, The First Affiliated Hospital of Guangzhou Medical University, Guangzhou, 510120, China.

${ }^{3}$ Department of Clinical Laboratory, The First Affiliated Hospital of Shenzhen University Health Science Center, Shenzhen, 518035, China.

${ }^{4}$ Shenzhen Children's Hospital, Shenzhen Engineering Laboratory for High-throughput Gene Sequencing of Pathogens, Shenzhen, 518038, China.

${ }^{5}$ State Key Laboratory of Infectious Disease Prevention and Control, Collaborative Innovation Center for Diagnosis and Treatment of Infectious Diseases, National Institute for Viral Disease Control and Prevention, Chinese Center for Disease Control and Prevention, 155 Changbai Rd, Beijing 102206, China.

${ }^{6}$ Department of Medical Laboratory, The Central Hospital of Wuhan, Tongji Medical College, Huazhong University of Science and Technology, Wuhan 430014, China.

${ }^{7}$ COVID-19 Research Center, Institute of Laboratory Medicine, Jinling Hospital, Nanjing University School of Medicine, Nanjing Clinical College of Southern Medical University, Nanjing, Jiangsu 210002, China;

${ }^{8}$ Joint Expert Group for COVID-19, Department of Laboratory Medicine \& Blood Transfusion, Wuhan Huoshenshan Hospital, Wuhan, Hubei 430100, China.

${ }^{9}$ Nano Science and Technology Institute, University of science and technology of China, Suzhou 215123, China.

*Correspondence to: B.S. (sunbaoqing@vip.163.com), H.W. (27whwh@sina.com), N.Z. (nanshan@vip.163.com), or H.M. (hwma2008@sinano.ac.cn)

$\dagger$ These three authors contributed equally. 
medRxiv preprint doi: https://doi.org/10.1101/2020.08.11.20172452; this version posted August 11, 2020. The copyright holder for this preprint (which was not certified by peer review) is the author/funder, who has granted medRxiv a license to display the preprint in perpetuity.

All rights reserved. No reuse allowed without permission.

\section{Supplementary Materials}

Fig. S1. Impact of cut-off value on the sensitivity and specificity of whole protein-based and PPHM assays.

Fig. S2. Diagnostic tools need to be used under proper conditions.

Fig. S3. Among the 80 patients with sequential serum samples available, 71 patients were sampled in their sero-positive period.

Fig. S4. Basic information of the 7 serum samples (dpo $>10)$ from 6 COVID-19 patients exhibited positive PPHMCOvID-19 results but negative RBD signal.

Fig. S5. Prolonging the incubation duration to improve the performance of PPHM detection.

Fig. S6. Basic information of the 35 suspected serum samples from 29 suspected subjects.

Fig. S7. For asymptomatic, moderate and severe patients, the detection performance of PPHMCOVID-19 is superior compared to a whole-protein (RBD)-based assay and a PCR assay.

Fig. S8. Three different dpo determination scenarios for symptomatic and asymptomatic patients.

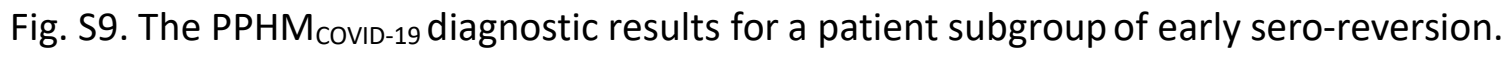

Fig. S10. Basic information of three patients exhibited negative PPHMcovID-19 but with paired positive PCR test results.

Fig. S11. Some peptides enter sero-positive period while RBD is still in its window period.

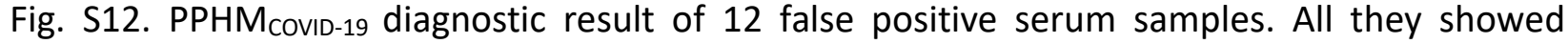
negative RBD results.

Fig. S13. Comparison of performance of SANE protocols that incorporates either PPHMcovID-9 or CLIA.

Table S1. Baseline characteristics of patients from the cross-sectional study.

Table S2. Amino acid sequence of eight probes for PPHM COVID-19.

Table S3. All 36 possible two-probe combinations of nine probes in our PPHMcovID-19.

Table S4. Impacts of variations in the population used for assay development on response rates for probes and PPHM.

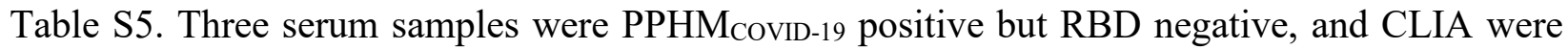
all borderline positive.

Table S6. Twenty-eight combinations of virus presence, antibody production, PCR and PPHM test results. 


\section{Supplementary Materials}

DMI significantly reduces the sensitivity- and specificity-related impacts of variations in the particular population used for assay development. In order to demonstrate the merit of using uniform cut-off value for individual probes, we listed response rates of all nine probes used

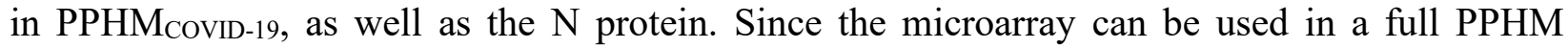
configuration or as discrete ELISA probes, we used RBD and N protein in a PPHM as discrete ELISA probes. In general, the density curve for the response rate of negative sera for one probe has two peaks and a long tail toward the right direction (Fig. S1). The first and high peak reflects the fact that most sera showed a near zero signal, and the second and low peak indicates the level of nonspecific interaction (NSI). The central value of the second peak varies for different probes, and may be correlated to their "immunogenicity", a general term used to describe/explain the ability/potential of a peptide/protein to activate the immune system/induce antibody production. The long tail toward the right side implies that NSI cannot be discriminated by signal (17).
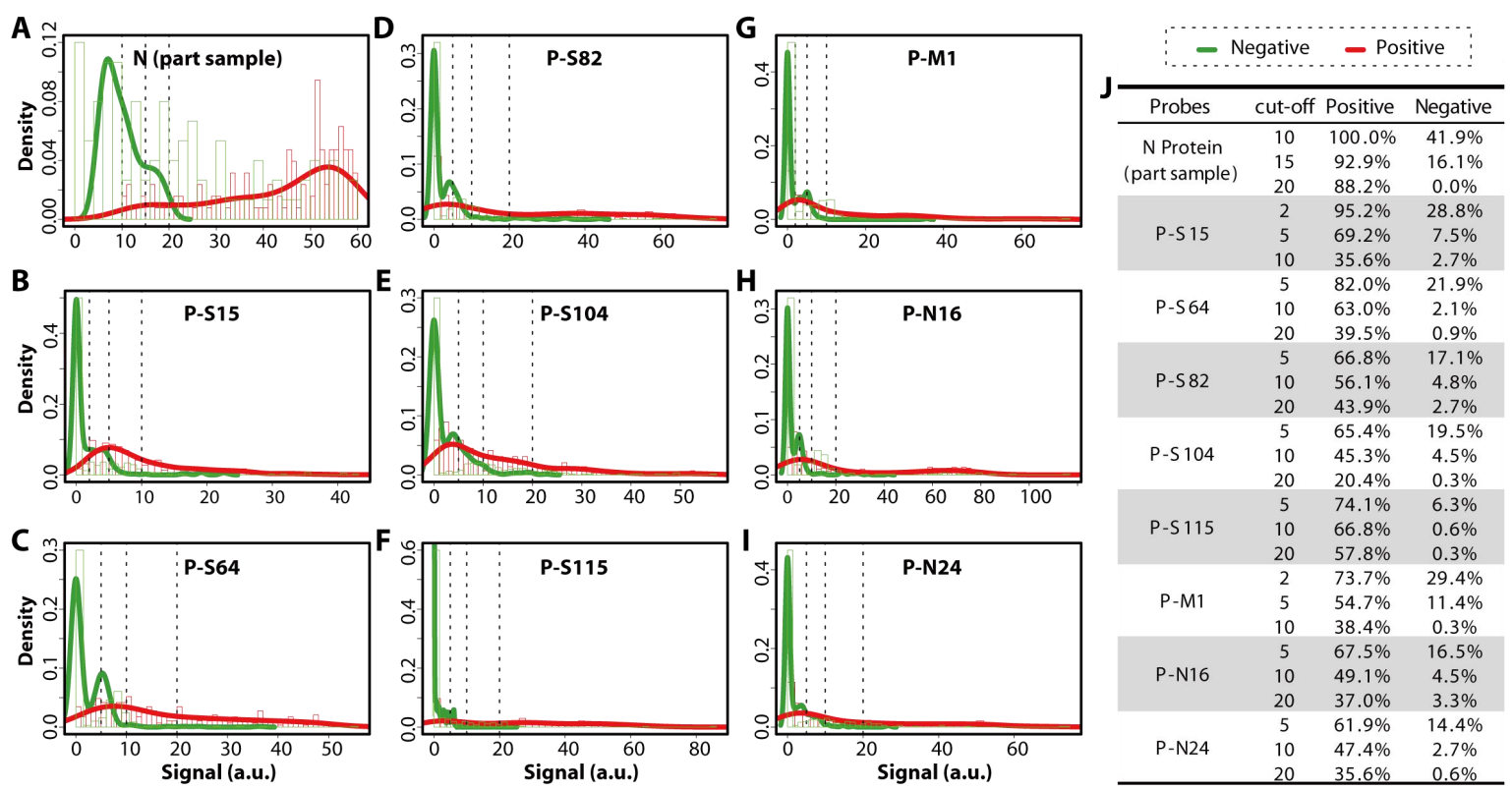

Fig. S1. Impact of cut-off value on the sensitivity and specificity of whole protein-based and PPHM assays. (A) Anti-(N protein) IgG signals for a subgroup comprising 94 control and 128 COVID-19 sera. (B)-(I) Results of antibody testing of other probes for a training group of 333 control and 289 COVID-19 serum samples. (J) List of response rates for different probes under different cut-off values. 
One of the reasons that cause sampling problems maybe the variety of conditions triggering hospital visit in daily practice, i.e., the various combinations of viral-status, sero-status, and disease-status upon sampling for clinical tests. For example, at sampling-4, Hosts 3 and 4 will have positive test results; Hosts 1 and 2 will have false negatives due to sampling in their window period; and Host 5 will have negative test results because sampling is conducted in the sero-negative period. However, at sampling-9, although most cohort samples will test positive due to overlap in the prolonged sero-positive period, some hosts, like Host 2, will show positive results due to sero-conversion, while others, e.g., Host 4, will have negative test results due to sero-reversion.

There are three goals to achieve, determining i) the presence of SARS-CoV-2; ii) the presence of anti-(SARS-CoV-2) IgG; iii) COVID-19. PCR-based assays can determine whether there is active SARS-CoV-2 infection. Since active SARS-CoV-2 infection is a necessary and sufficient condition for being COVID-19 patient, positive PCR test results can be used to diagnose COVID-19. However, a host could be a COVID-19 patient after SARS-CoV-2 clearance, i.e., negative PCR test result due to sampling in viral-absence period would deliver a false negative CVOID-19 result.

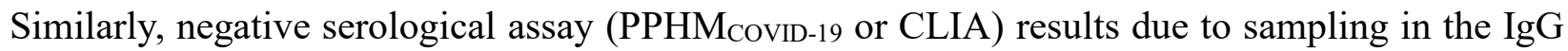
production window period of SARS-CoV-2 infection are true negative in term of IgG production, however, are false negative results for COVID-19 diagnosis. Thus, we define all test results referring to COVID-19 diagnosis unless otherwise indicated. 
A

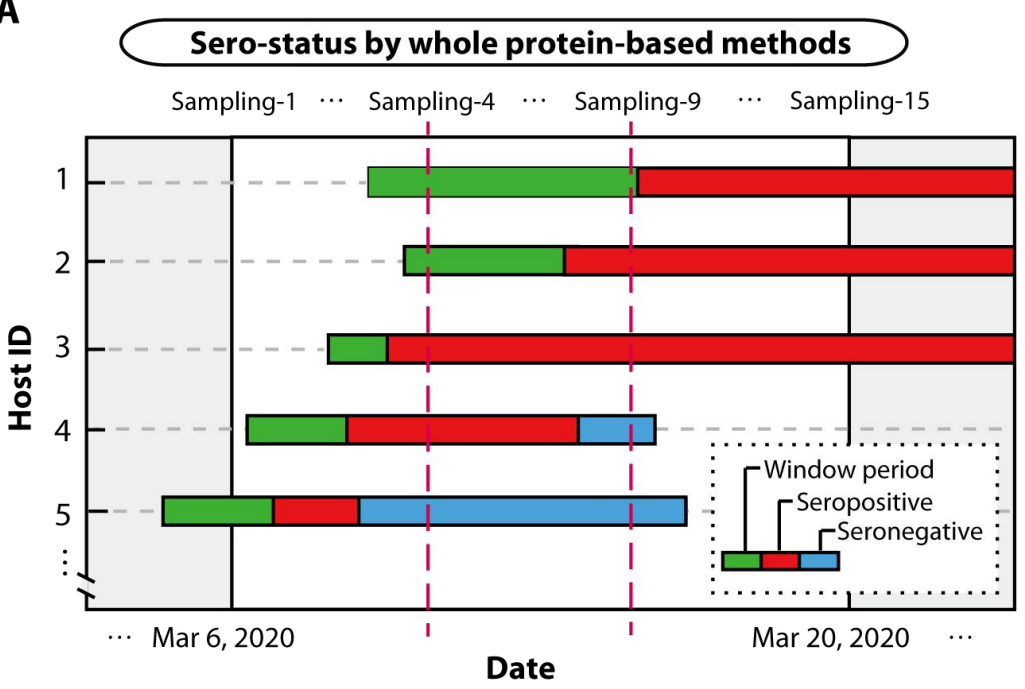

B

\begin{tabular}{|c|c|c|c|}
\hline Goal $^{a}$ & Tool & Principles & Problems \\
\hline SARS-CoV-2 & PCR-based assays & Sequence uniqueness & $\begin{array}{c}\text { False negative especially in } \\
\text { non-invasive sampling }\end{array}$ \\
\hline $\begin{array}{l}\text { Anti-RBD } \\
\operatorname{lgGs} b\end{array}$ & $\begin{array}{l}\text { Whole protein-based } \\
\text { methodsc }\end{array}$ & $\begin{array}{l}\text { A casual relationship }{ }^{b} \text { and } \\
\text { specificity of lgGs }\end{array}$ & $\begin{array}{l}\text { Cut-off value associated sensitivity } \\
\text { and specificity problems }\end{array}$ \\
\hline $\lg G s d$ & PPHM & $\begin{array}{l}\text { A casual relationshipd and probability } \\
\text { of related and irrelevant events }\end{array}$ & Window period \\
\hline COVID-19 & $\begin{array}{l}\text { A diagnostic decision- } \\
\text { making protocol }\end{array}$ & / & $\begin{array}{l}\text { Ample combinations between } \\
\text { disease-, viral-, and sero-status }\end{array}$ \\
\hline
\end{tabular}

${ }^{\text {a }}$ To confirm or refute the presence of...

${ }^{\mathrm{b}} \mathrm{A}$ casual relationship between SARS-CoV-2 infection and production of anti-RBD IgGs.

'Lateral flow assays, ELISA (enzyme-linked immunosorbent assays), and chemiluminescent immunoassays...

${ }^{d}$ Antibodies produced in response to SARS-CoV-2 infection. Nonspecific interaction related false positive (specificity problem)

Fig. S2. Diagnostic tools need to be used under proper conditions. (A) Schematic illustration of serum sampling marked by date. Cohort sera collected at any given date will contain samples from all three stages of sero-status, regardless of whether the dpo is identical among samples. (B) Different diagnostic goals should be selected for different detection tools. 
Of the 414 confirmed COVID-19 patients, we had access to sequential serum samples for 80 . Among these, 71 patients were sampled within their sero-positive period.

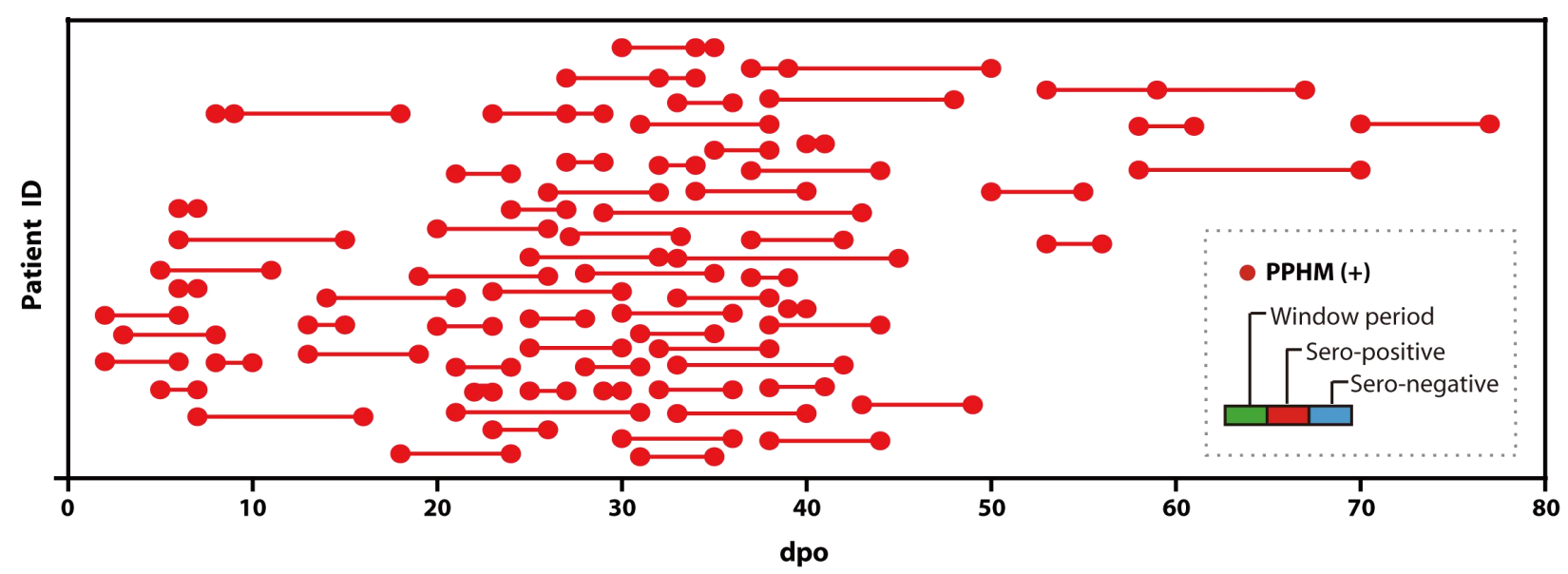

Fig. S3. Among the 80 patients with sequential serum samples available, 71 patients were sampled in their sero-positive period. 
medRxiv preprint doi: https://doi.org/10.1101/2020.08.11.20172452; this version posted August 11, 2020. The copyright holder for this preprint (which was not certified by peer review) is the author/funder, who has granted medRxiv a license to display the preprint in perpetuity.

All rights reserved. No reuse allowed without permission.

We found seven serum samples $(\mathrm{dpo}>10)$ that have clear PCR negative time. Among them, three serum samples (Serum-4-11dpo, Serum-85-27dpo, and Serum-132-42dpo) were collected on the day or after the day that PCR turned into negative, which we suspected are the sera from patients characterized by anti-RBD IgG fast disappearing. Serum-41-15dpo and Serum-64-14dpo,

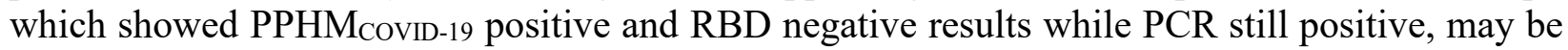
caused by PCR testing not frequent enough so that the exact date of viral clearance should be earlier than the serum sampling time. In contrast, Serum-48-40dpo and Serum-132-37dpo with the late dpo, are easily determined to be in their sero-negative period, and PCR testing were not frequent enough. Therefore, we proposed these seven serum samples were not in the window period of RBD, and such results indicated pathogen-derived peptides have longer sero-positive period than RBD (whole protein).

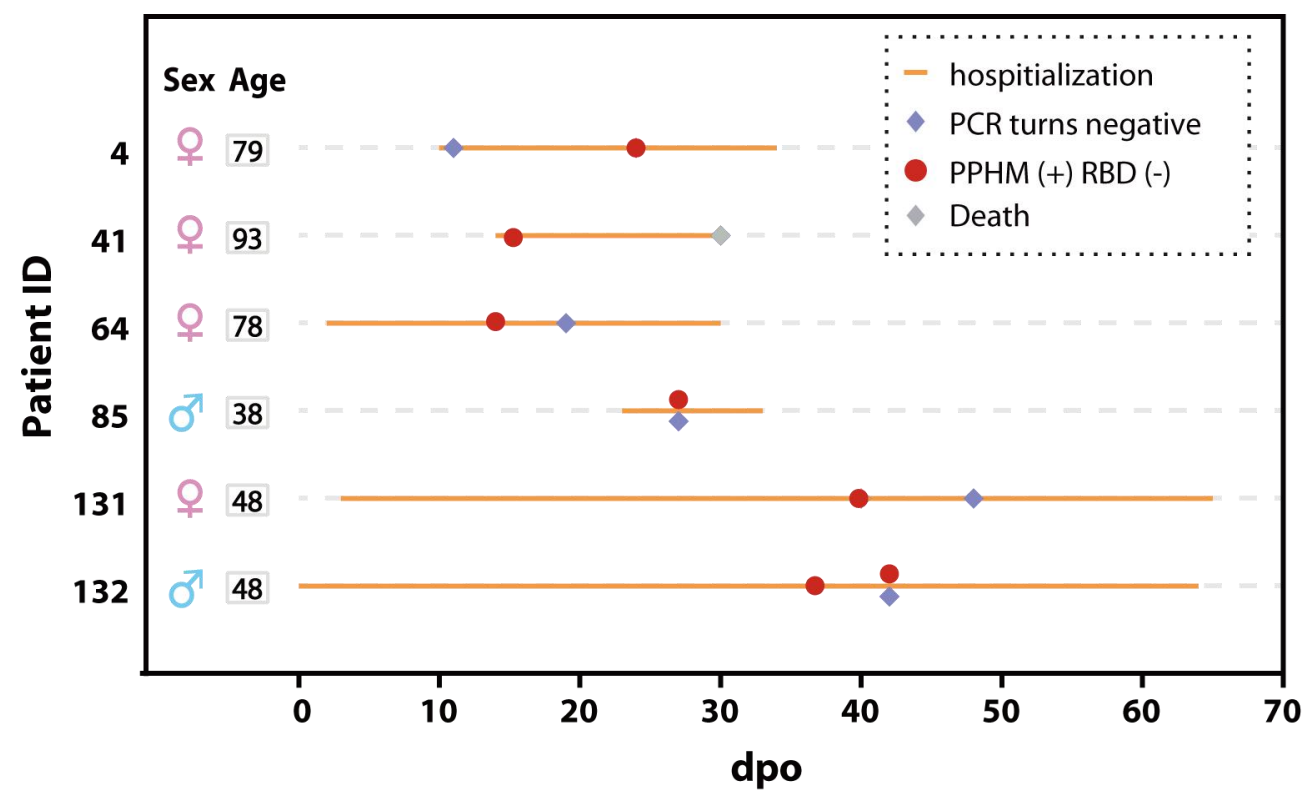

Fig. S4. Basic information of the 7 serum samples (dpo $>10)$ from 6 COVID-19 patients exhibited positive PPHMcoviD-19 results but negative RBD signal. 
The rationale underlying the design of the high sensitivity iteration of PPHMCOvID-9 assay, was based on two accepted principles of immunology. i) IgGs produced in the window period are low in both concentration and affinity; ii) IgGs produced around the sero-reversion point are also low in concentration but exhibit high affinity. Based on the observation that IgGs with high affinity but low concentration (cognate Ab-Ag pairs) can be detected after a prolonged chip incubation with sera, while the detection of low affinity IgGs (non-specific interaction Ab-Ag pairs) is not affected by incubation time, we designed the high-sensitivity iteration of PPHM COVID-9 $_{\text {test }}$ to diagnose serum samples collected either in the window period or around the sero-reversion point. For example, Patient-165, 42, and Neg1 that were in sero-negative period, window period, and confirmed other etiology, respectively, were tested using the high-sensitivity iteration of PPHMCOvid-9. Patient-165 at 27 dpo showed an enhanced response of two probes (P-S15 and P$\mathrm{S} 64)$, i.e., DMI changed from 0 to 2. Patient-Neg1 with other etiology remained as negative under both conditions, supporting our design rationale. Further, these results offer experimental confirmation that longer incubation durations can indeed increase the sensitivity of PPHM probes.

A

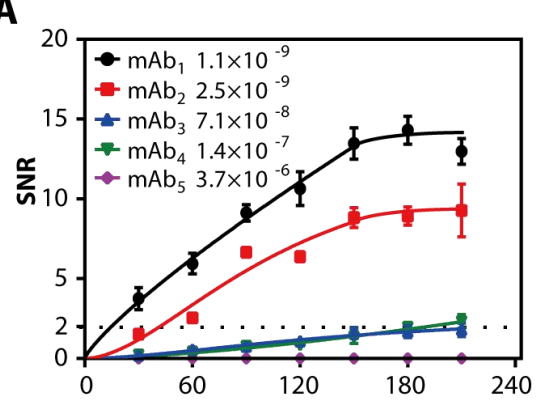

B

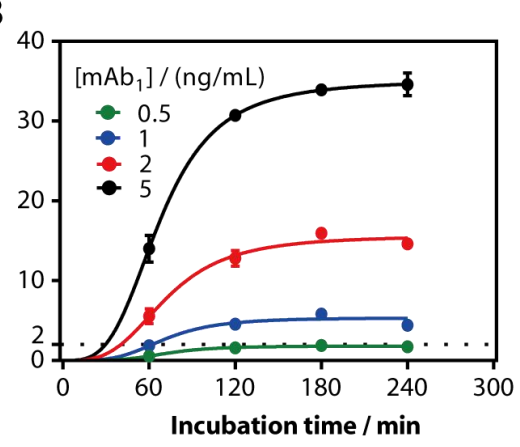

C

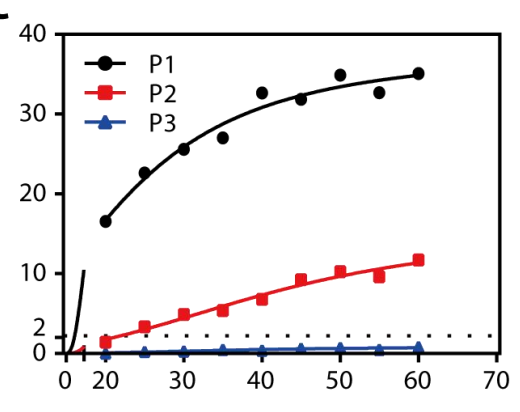

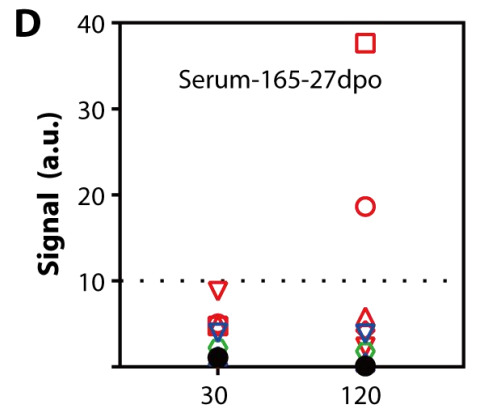
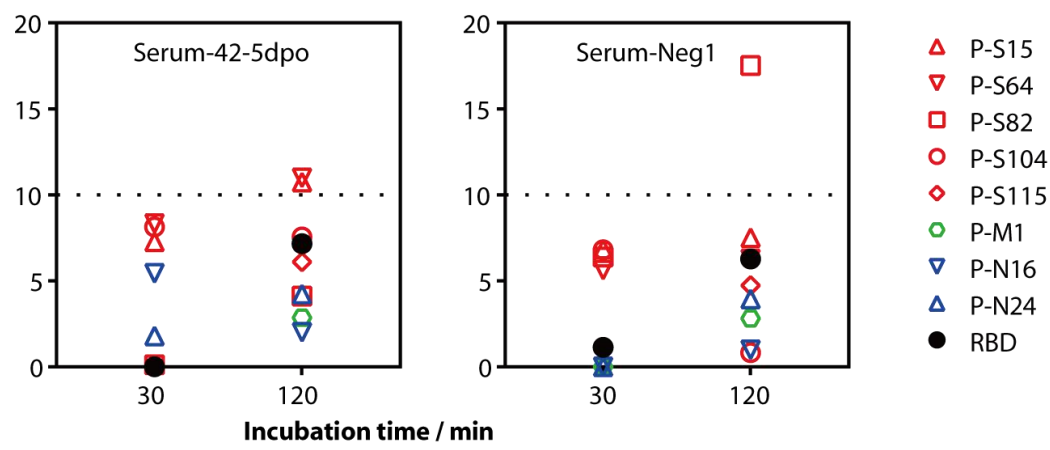

Fig. S5. Prolonging the incubation duration to improve the performance of PPHM detection. We obtained five monoclonal antibodies (mAb1 mAb5) with different affinity for the same short peptide P1 (DQPQNLEEILMHCQT) by the classical mouse hybridoma method. (A) At the same antibody concentration $(5 \mathrm{ng} / \mathrm{mL})$, the response characteristics of different affinity $\mathrm{mAbs}$ are different. (B) At different concentrations of the same mAb (i.e., the same affinity), the response characteristics are different. $(\mathbf{C})$ Demonstrates the response of $\mathrm{mAb} 1$ to cognate short peptide P1 and non-cognate short peptides P2 and P3. (D) Example: Patient-165 in late dpo has three probes converted from negative to positive, Patient-42 in early dpo has two probes converted, and Patient-Neg1 of other etiology is negative for all probes. After prolonging the incubation time One probe turns positive, but does not affect the detection result (still negative). The dotted line indicates the cut-off value. 
medRxiv preprint doi: https://doi.org/10.1101/2020.08.11.20172452; this version posted August 11, 2020. The copyright holder for this preprint (which was not certified by peer review) is the author/funder, who has granted medRxiv a license to display the preprint in perpetuity.

All rights reserved. No reuse allowed without permission.

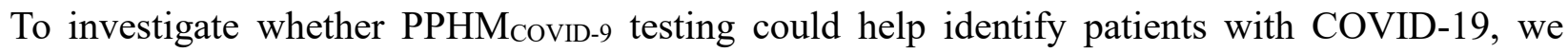
screened 29 suspected subjects, with 26 who displayed symptoms of COVID-19 and another 3 without symptoms of COVID-19 yet who showed abnormal radiological findings; all of these subjects were viral RNA negative based on 111 testing; some showed more than one negative test.

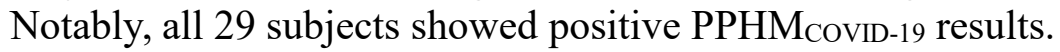

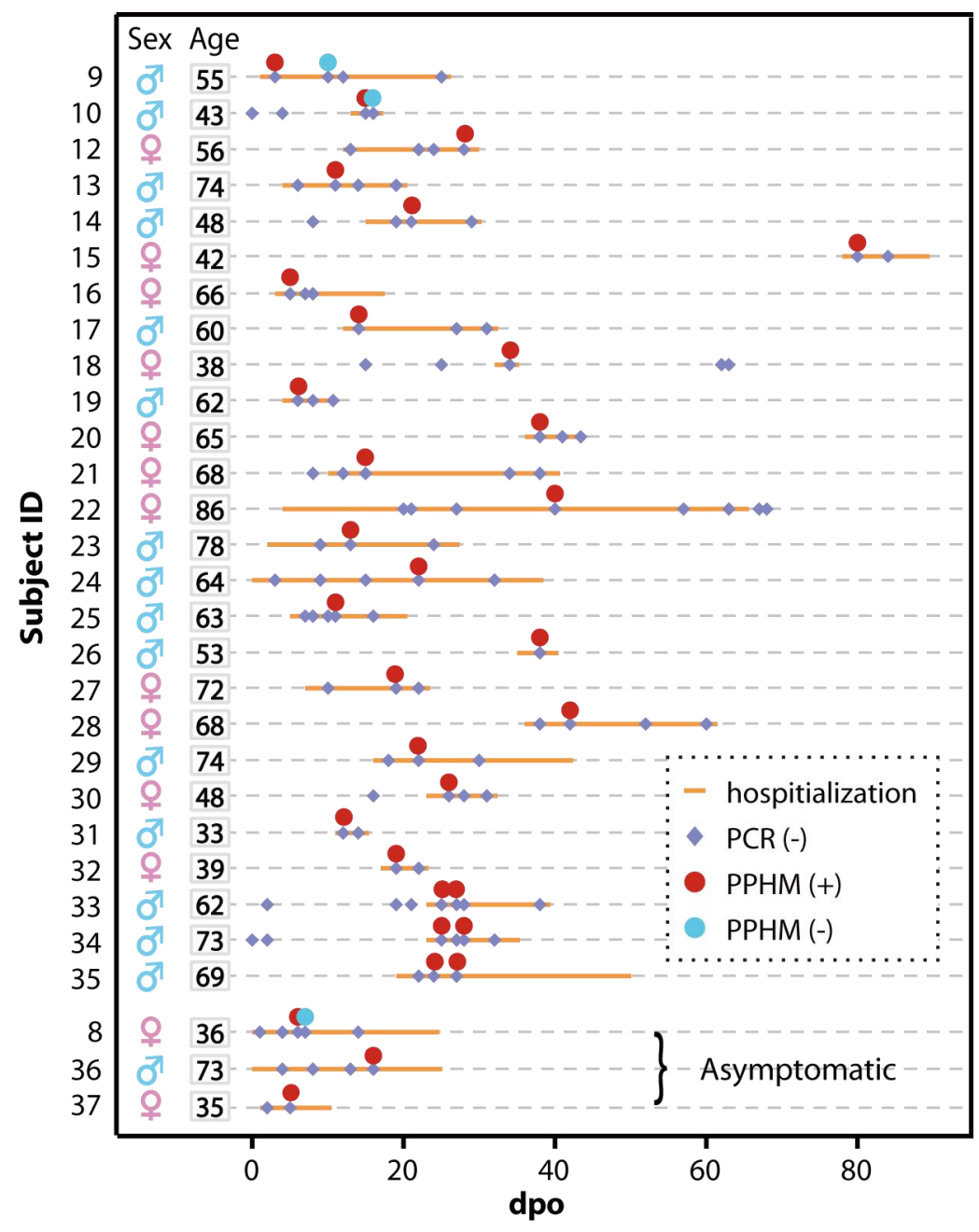

Fig. S6. Basic information of the 35 suspected serum samples from 29 suspected subjects. 
A
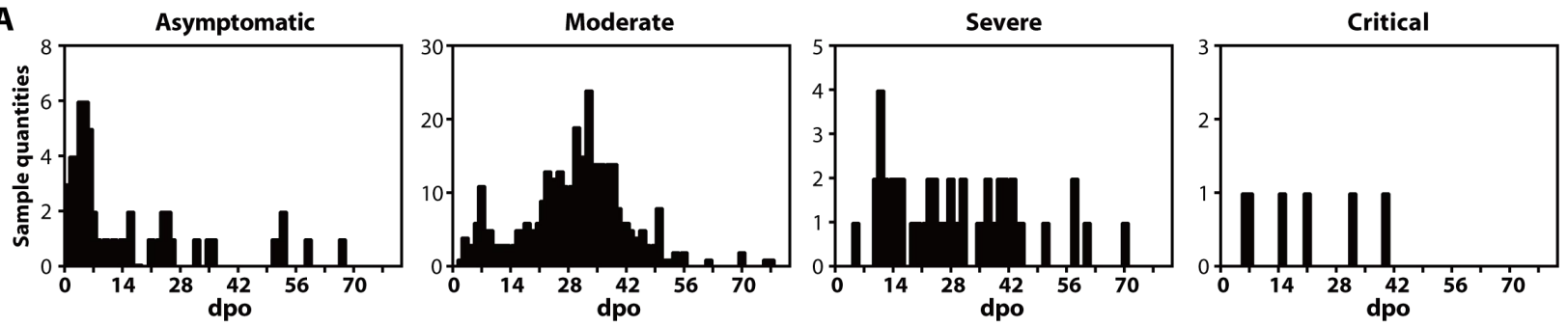

B
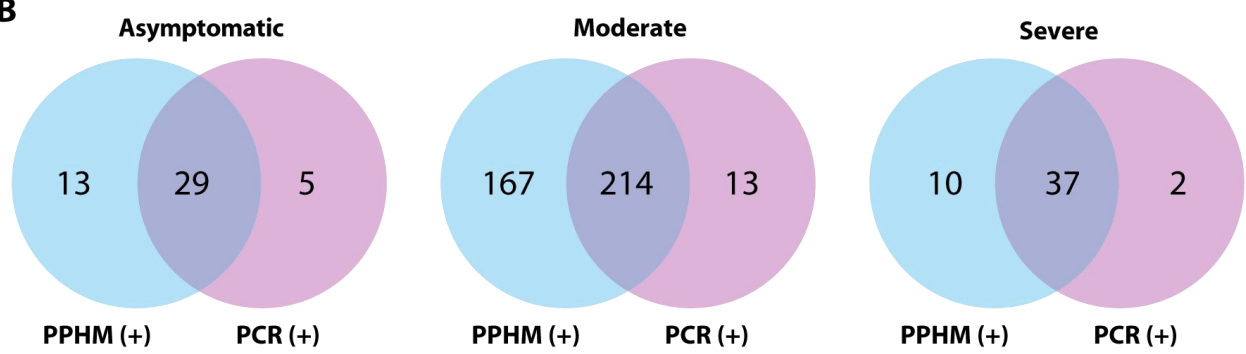

Fig. S7. For asymptomatic, moderate and severe patients, the detection performance of

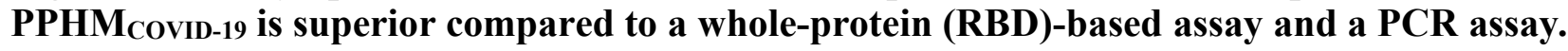
(A) The dpo distribution of four clinical patients. (B) Comparison of PPHM and PCR detection results as Venn diagrams for asymptomatic, moderate, and severe patients. 
There are three scenarios in this study that require different dpo determination. The diagnosis is initiated i) by the subject him/herself upon the onset of symptoms. When the subject is confirmed as COVID-19 by PCR-based assay or other criterion, the dpo is recorded based on self-reporting from the patient (Fig. S8, black line). ii)-iii), by the subject upon confirmation with close contact history. According the guideline V7, if the subject is confirmed by positive PCR result, the date first positive PCR test result obtained is determined as $1 \mathrm{dpo}$, thus dpo is relative uncertain (Fig. $\mathrm{S} 8$, blue line). If a negative PCR test result but positive radiology result, the date first positive radiology result obtained is determined as 1dpo (Fig. S8, green line). If the dpi date could be affirmatively confirmed, dpo of three scenarios could be compared (Fig. S8, red line).

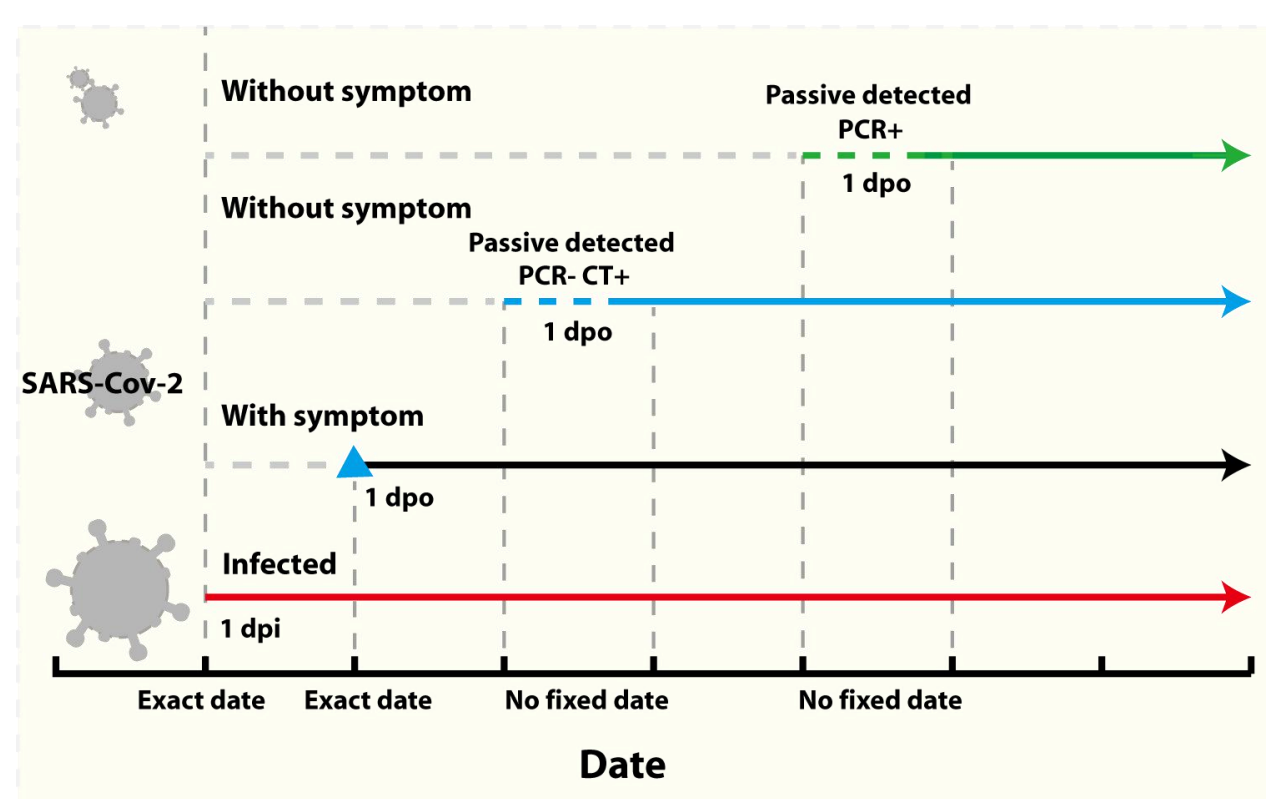

Fig. S8. Three different dpo determination scenarios for symptomatic and asymptomatic patients. 


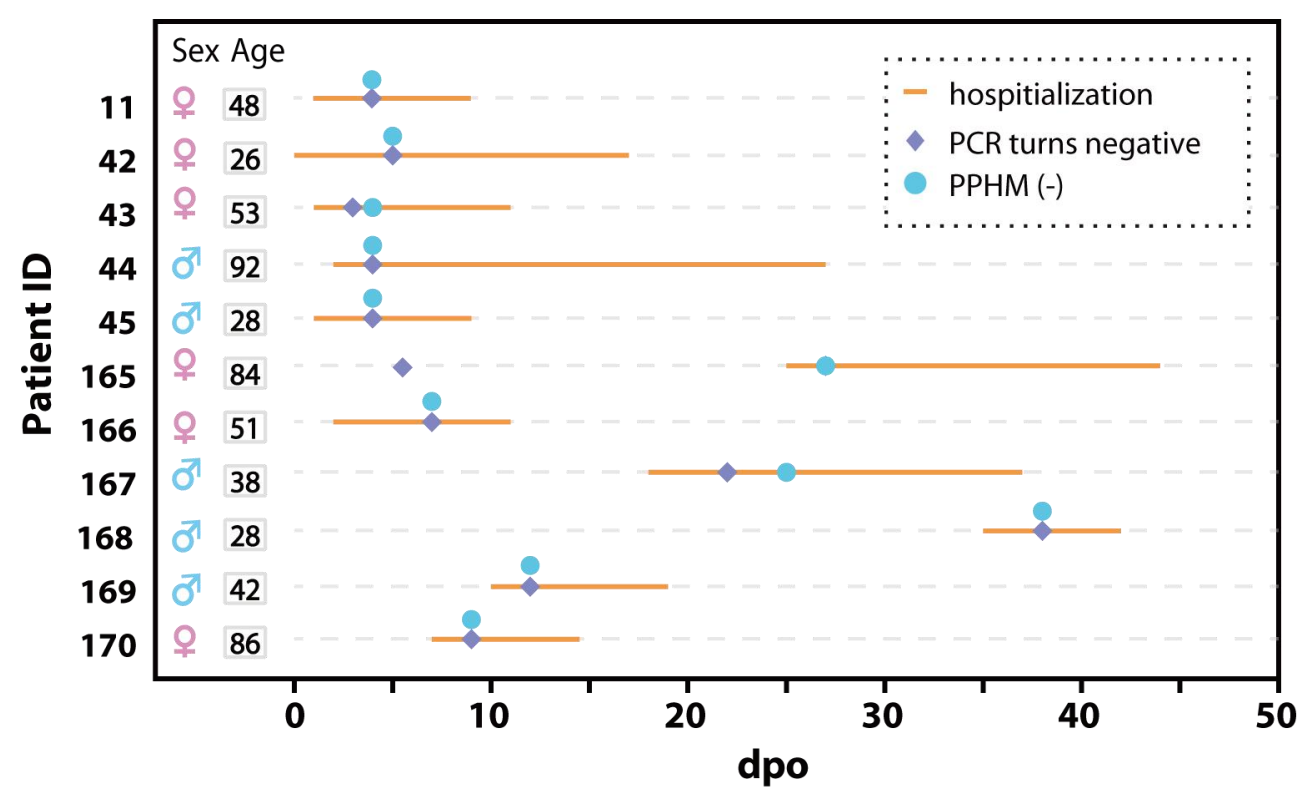

Fig. S9. The PPHM 

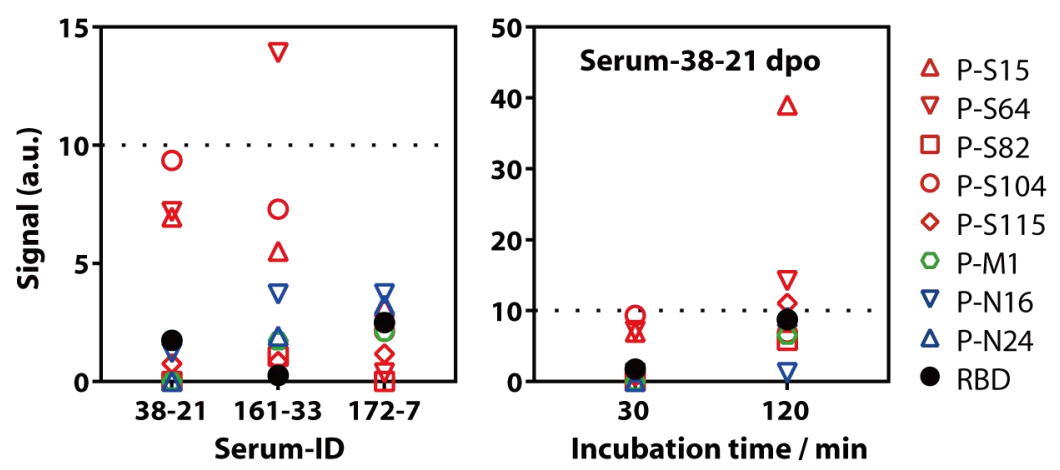

\begin{tabular}{ccccccccc}
\hline Patient ID & dpo & Gender & Age & Severity & PCR & IgM & IgG & IgA \\
\hline 38 & 21 & Female & 86 & critical & + & 0.22 & 0.14 & 0.18 \\
161 & 33 & Female & 67 & moderate & + & 0.21 & 0.18 & 0.21 \\
172 & 7 & Female & 34 & moderate & + & 0.08 & 0.09 & 0.14 \\
\hline
\end{tabular}

Fig. S10. Basic information of three patients exhibited negative PPHMCovID-19 but with paired positive PCR test results. 
From two patients with sequential serum samples, we observed that anti-peptide IgGs entered into the sero-positive period while RBD is still in its window period.
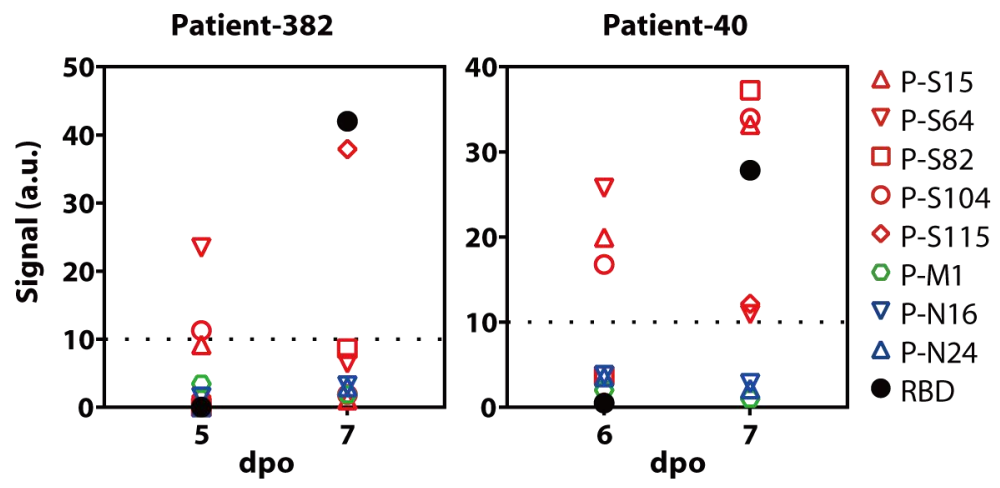

\begin{tabular}{ccccccccc}
\hline Patient ID & dpo & Gender & Age & Severity & PCR & IgM & IgG & IgA \\
\hline \multirow{2}{*}{382} & 5 & \multirow{2}{*}{ Male } & \multirow{2}{*}{82} & \multirow{2}{*}{ moderate } & - & 0.13 & 0.19 & 0.16 \\
& 7 & & & & - & 47.12 & 37.53 & 41.67 \\
\multirow{2}{*}{40} & 6 & \multirow{2}{*}{ Male } & \multirow{2}{*}{90} & \multirow{2}{*}{ critical } & + & 0.08 & 0.56 & 0.25 \\
& 7 & & & & & & & \\
\end{tabular}

Fig. S11. Some peptides enter sero-positive period while RBD is still in its window period. 
medRxiv preprint doi: https://doi.org/10.1101/2020.08.11.20172452; this version posted August 11, 2020. The copyright holder for this preprint (which was not certified by peer review) is the author/funder, who has granted medRxiv a license to display the preprint in perpetuity. All rights reserved. No reuse allowed without permission.

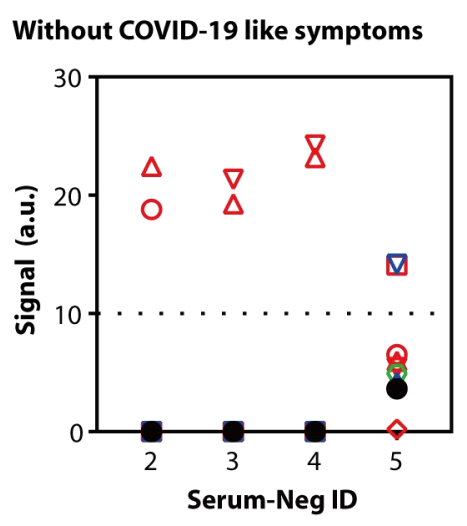

With COVID-19 like symptoms

Fig S12. PPHMCovid-19 diagnostic results of 12 false positive serum samples. All showed negative anti-RBD IgG results. 
medRxiv preprint doi: https://doi.org/10.1101/2020.08.11.20172452; this version posted August 11, 2020. The copyright holder for this preprint (which was not certified by peer review) is the author/funder, who has granted medRxiv a license to display the preprint in perpetuity.

All rights reserved. No reuse allowed without permission.

Of the 473 total control serum samples, 12(12/473, 2.5\%) showed false positive PPHM results (Fig. S12). All twelve serum samples can be determined as false positive through RBD negative in addition to epidemiological history. Of the nine, six were SLE patients, three were healthy, in agreement with our previous results supporting that it is not possible to predict when and where NSI/USI will happened, thus posing serious problems to present serological assays (17). PPHM can reduce the frequency by using multiple probes. $\mathrm{N}$ protein is less specific thus is not used. As SARS-CoV-2 continues to spread, the specificity of RBD is expected to decrease, implying RBD may not be suitable for future diagnosis of COVID-19.

We demonstrated, through the comparison of two SANE protocols that incorporated PPHMCOVID19 and CLIA, respectively, that PPHMCOvID-19 is essential for achieving full sensitivity and specificity. For outpatients with COVID-19-like symptoms, while CLIA is incapable of distinguish false positive and positive testing results resulting in 13 ambiguity cases (Fig. S13B),

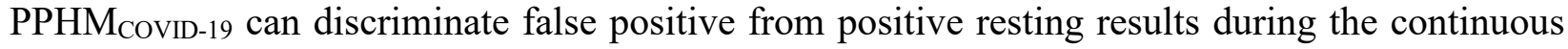
monitoring step because false positive will remain RBD negative (Fig. S13A). Although in SANE protocol using PPHMCOVID-19 will have more enrollments than using CLIA, i.e., 57 vs 40, these outpatients will need self-isolation or quarantine anyway. The reason we can determine

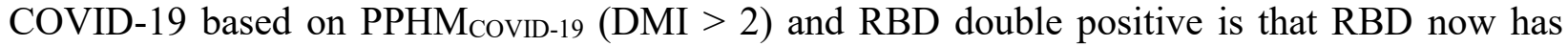
extremely high specificity so for one negative serum to be both PPHM COVID-19 $_{\text {and RBD false }}$ positive is almost impossible (3 independent events to simultaneously happen). Similarly, for outpatients without COVID-19-like symptoms, SANE protocol using CLIA produced 2 ambiguity cases (Fig. S13D) that are both confirmed as COVID-19 cases by the SANE protocol using PPHMCOVID-19 (Fig. S13C). 


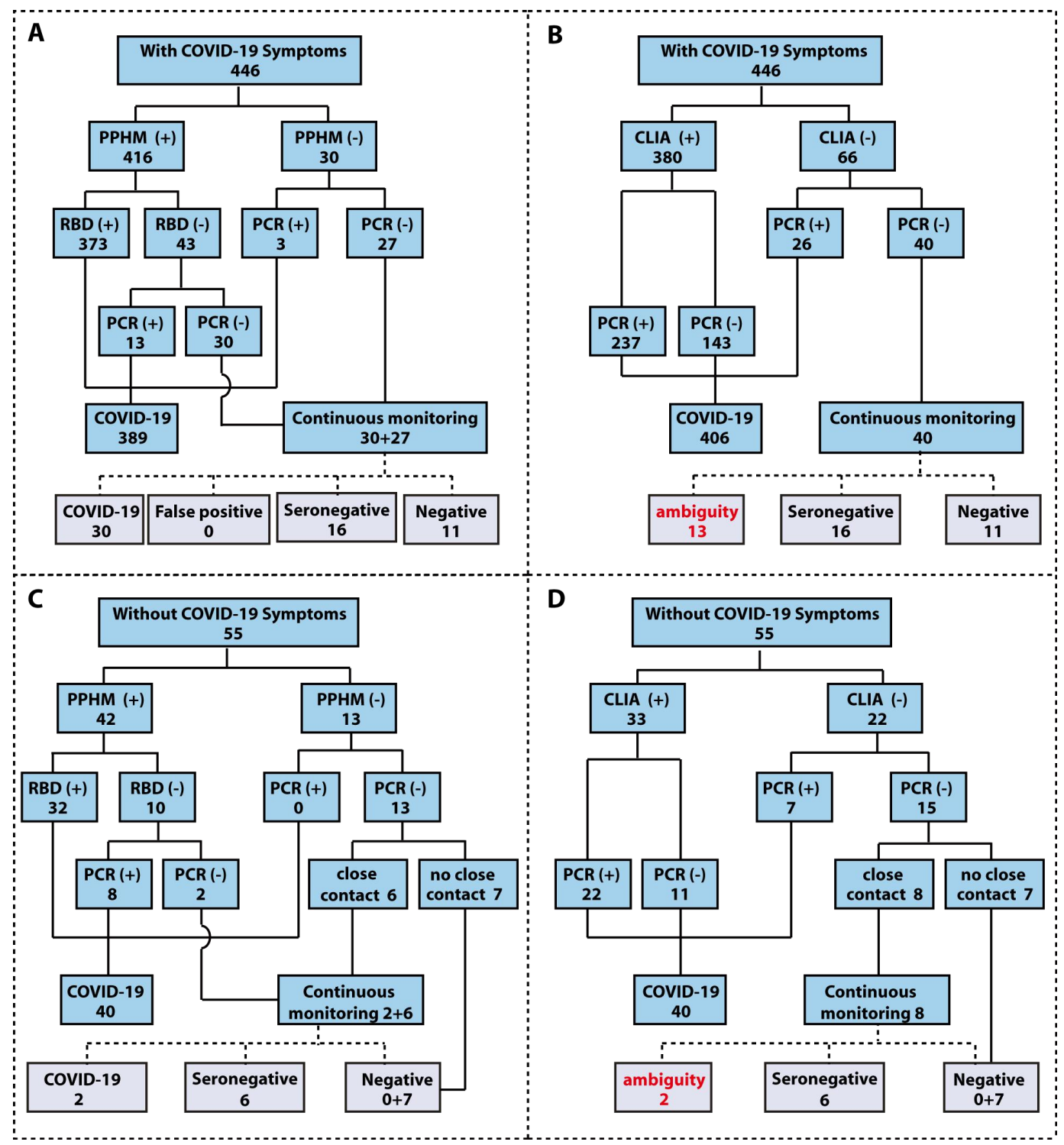

Fig. S13. Comparison of performance of SANE protocols that incorporates either PPHMCovid-9 or CLIA. (A) The result of SANE protocol combined PPHMCOvID-19 and PCR in 446 serum samples from the patient with COVID-19 like symptoms. (B) Matched CLIA results. (C) The result of SANE protocol combined PPHM Covid-19 and PCR in 55 serum samples from the patient without COVID-19 like symptoms. (D) Matched CLIA results. 
Table S1. Baseline characteristics of patients from the cross-sectional study.

\begin{tabular}{llllll}
\hline Number (\%) & All & Asymptomatic & Moderate & Severe/critical & P value \\
\hline & 414 & $41(9.9 \%)$ & $326(78.7 \%)$ & $47(11.4 \%)$ & \\
Age & $55.86 \pm 18.67$ & $56.49 \pm 22.68$ & $57.17 \pm 16.34$ & $46.17 \pm 26.25$ & $2.84 \mathrm{E}-02 *$ \\
Gender & & & & & \\
$\quad$ Female & $229(55.3 \%)$ & $26(6.3 \%)$ & $179(43.2 \%)$ & $24(5.8 \%)$ & $4.83 \mathrm{E}-01$ \\
$\quad$ Male & $185(44.7 \%)$ & $15(3.6 \%)$ & $147(35.5 \%)$ & $23(5.6 \%)$ & \\
Comorbidities & & & & & \\
Hypertension & $148(35.7 \%)$ & $15(3.6 \%)$ & $119(28.7 \%)$ & $14(3.4 \%)$ & $6.64 \mathrm{E}-01$ \\
Cardiovascular disease & $56(13.5 \%)$ & $6(1.4 \%)$ & $45(10.9 \%)$ & $5(1.2 \%)$ & $5.48 \mathrm{E}-02$ \\
Diabetes & $73(17.6 \%)$ & $11(2.7 \%)$ & $50(12.1 \%)$ & $12(2.9 \%)$ & $6.11 \mathrm{E}-02$ \\
hyperlipemia & $16(3.9 \%)$ & $2(0.5 \%)$ & $12(2.9 \%)$ & $2(0.5 \%)$ & $6.92 \mathrm{E}-01$ \\
Chronic Gastritis & $32(7.7 \%)$ & $0(0.0 \%)$ & $25(6.0 \%)$ & $7(1.7 \%)$ & $1.57 \mathrm{E}-01$ \\
Malignancy & $19(4.6 \%)$ & $3(0.7 \%)$ & $14(3.4 \%)$ & $2(0.5 \%)$ & $1.00 \mathrm{E}+00$ \\
COPD & $16(3.9 \%)$ & $2(0.5 \%)$ & $13(3.1 \%)$ & $1(0.2 \%)$ & $1.00 \mathrm{E}+00$ \\
Chronic kidney disease & $16(3.9 \%)$ & $3(0.7 \%)$ & $10(2.4 \%)$ & $3(0.7 \%)$ & $2.17 \mathrm{E}-01$ \\
Chronic liver disease & $8(1.9 \%)$ & $0(0.0 \%)$ & $6(1.4 \%)$ & $2(0.5 \%)$ & $2.66 \mathrm{E}-01$ \\
Signs and symptoms & & & & & \\
Fever & $244(58.9 \%)$ & $0(0.0 \%)$ & $207(50.0 \%)$ & $37(8.9 \%)$ & $4.85 \mathrm{E}-02 *$ \\
Fatigue & $188(45.4 \%)$ & $0(0.0 \%)$ & $159(38.4 \%)$ & $29(7.0 \%)$ & $1.19 \mathrm{E}-01$ \\
Dry cough & $230(55.6 \%)$ & $0(0.0 \%)$ & $195(47.1 \$)$ & $35(8.5 \%)$ & $5.58 \mathrm{E}-02$ \\
Anorexia & $110(26.6 \%)$ & $0(0.0 \%)$ & $98(23.7 \%)$ & $12(2.9 \%)$ & $6.10 \mathrm{E}-01$ \\
Diarrhea & $37(8.9 \%)$ & $0(0.0 \%)$ & $36(8.7 \%)$ & $1(0.2 \%)$ & $6.55 \mathrm{E}-02$ \\
Pharyngalgia & $19(4.6 \%)$ & $0(0.0 \%)$ & $17(4.1 \%)$ & $2(0.5 \%)$ & $1.00 \mathrm{E}+00$ \\
Palpitation & $19(4.6 \%)$ & $0(0.0 \%)$ & $17(4.1 \%)$ & $2(0.5 \%)$ & $1.00 \mathrm{E}+00$ \\
Chest stuffiness & $79(19.1 \%)$ & $0(0.0 \%)$ & $72(17.4 \%)$ & $7(1.7 \%)$ & $3.40 \mathrm{E}-01$ \\
Onset of symptom & $28.94 \pm 14.99$ & $13.83 \pm 14.84$ & $29.08 \pm 12.76$ & $41.11 \pm 17.90$ & $4.34 \mathrm{E}-14$ \\
Hospital admission & $16.62 \pm 13.74$ & $5.15 \pm 8.52$ & $18.54 \pm 14.07$ & $13.32 \pm 8.94$ & $5.26 \mathrm{E}-12$ \\
\hline aA & & & &
\end{tabular}

"Age": There are significant differences among the three groups, p-value $<0.05$

"Fever": There are significant differences among "Moderate" and "Severe/critical", p-value $<0.05$

"Onset of symptom", "Hospital admission": Very significant difference among the three groups, p-value $<0.01$

The chi-squared test was used to compare qualitative data and the Kruskal-Wallis H test was used for comparison continuous data between multiple groups. Fisher's exact test was used to compare "Moderate" and "Severe/critical" which the quantity less than 5. 
medRxiv preprint doi: https://doi.org/10.1101/2020.08.11.20172452; this version posted August 11, 2020. The copyright holder for this preprint (which was not certified by peer review) is the author/funder, who has granted medRxiv a license to display the preprint in perpetuity.

All rights reserved. No reuse allowed without permission.

Table S2. Amino acid sequence of eight probes for PPHMCOvID-19.

\begin{tabular}{ccc}
\hline Probe & Amino acid sequence & Region \\
\hline P-S15 & LGVYYHKNNKSWMESEFRVY & $141-160$ \\
P-S64 & PTWRVYSTGSNVFQTRAGCL & $631-650$ \\
P-S82 & KPSKRSFIEDLLFNKVTLAD & $811-830$ \\
P-S104 & ECVLGQSKRVDFCGKGYHLM & $1031-1050$ \\
P-S115 & LQPELDSFKEELDKYFKNHT & $1141-1160$ \\
P-M1 & MADSNGTITVEELKKLLEQW & $1-20$ \\
P-N16 & PANNAAIVLQLPQGTTLPKG & $151-170$ \\
P-N24 & ESKMSGKGQQQQGQTVTKKS & $231-250$ \\
\hline
\end{tabular}




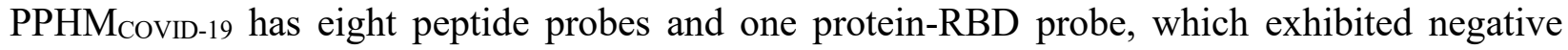
response rates ranging from $0.3 \%$ to $5 \%$, and positive response rates ranging from $36 \%$ to $85 \%$ (Fig. 1H). For the 333 control serum samples, P-S82, P-S104, and P-N16 have 16(5\%), 15(5\%), and $15(5 \%)$ responding samples, respectively (Fig. $1 \mathrm{H})$.

For $\mathrm{DMI}=2$, there are 36 possible combinations (Table S3). The predicted values of three combinations, namely (P-S82, P-S104), (P-S82, P-N16), and (P-N16, P-S104), are all roughly $0.25 \%(1 / 333)$. The experimental values are all roughly $0.9 \%$ (3 or $2 / 333)$. The overall specificity and sensitivity for DMI $=2$ are $2.7 \%(9 / 333)$, which is lower than negative response rates of five probes, and 92\% (267/289), which is higher than positive response rates of all nine response rate.

Table S3. All 36 possible two-probe combinations of nine probes in our PPHMCovid-19.

\begin{tabular}{|c|c|c|c|c|}
\hline \multirow{2}{*}{$\begin{array}{c}\text { DMI }=2 \\
\text { Response }\end{array}$} & \multicolumn{2}{|c|}{ Control $(n=333)$} & \multicolumn{2}{|c|}{ Positive $(n=289)$} \\
\hline & Number & Rate & Number & Rate \\
\hline P-S15, P-S64 & 2 & $1 \%$ & 92 & $32 \%$ \\
\hline P-S15, P-S82 & 0 & $0 \%$ & 57 & $20 \%$ \\
\hline P-S15, P-S104 & 1 & $0 \%$ & 92 & $32 \%$ \\
\hline P-S15, P-S115 & 0 & $0 \%$ & 68 & $24 \%$ \\
\hline P-S15, P-M1 & 0 & $0 \%$ & 37 & $13 \%$ \\
\hline P-S15, P-N16 & 0 & $0 \%$ & 55 & $19 \%$ \\
\hline P-S15, P-N24 & 0 & $0 \%$ & 50 & $17 \%$ \\
\hline P-S15, RBD & 0 & $0 \%$ & 84 & $29 \%$ \\
\hline P-S64, P-S82 & 0 & $0 \%$ & 106 & $37 \%$ \\
\hline P-S64, P-S104 & 0 & $0 \%$ & 112 & $39 \%$ \\
\hline P-S64, P-S115 & 0 & $0 \%$ & 127 & $44 \%$ \\
\hline P-S64, P-M1 & 0 & $0 \%$ & 75 & $26 \%$ \\
\hline P-S64, P-N16 & 0 & $0 \%$ & 98 & $34 \%$ \\
\hline P-S64, P-N24 & 0 & $0 \%$ & 96 & $33 \%$ \\
\hline P-S64, RBD & 0 & $0 \%$ & 161 & $56 \%$ \\
\hline P-S82, P-S104 & 0 & $0 \%$ & 68 & $24 \%$ \\
\hline P-S82, P-S115 & 0 & $0 \%$ & 132 & $46 \%$ \\
\hline P-S82, P-M1 & 0 & $0 \%$ & 85 & $29 \%$ \\
\hline P-S82, P-N16 & 1 & $0 \%$ & 96 & $33 \%$ \\
\hline P-S82, P-N24 & 1 & $0 \%$ & 97 & $34 \%$ \\
\hline P-S82, RBD & 0 & $0 \%$ & 161 & $56 \%$ \\
\hline P-S104, P-S115 & 0 & $0 \%$ & 92 & $32 \%$ \\
\hline P-S104, P-M1 & 0 & $0 \%$ & 50 & $17 \%$ \\
\hline P-S104, P-N16 & 1 & $0 \%$ & 62 & $21 \%$ \\
\hline P-S104, P-N24 & 1 & $0 \%$ & 62 & $21 \%$ \\
\hline P-S104, RBD & 0 & $0 \%$ & 113 & $39 \%$ \\
\hline P-S115, P-M1 & 0 & $0 \%$ & 101 & $35 \%$ \\
\hline P-S115, P-N16 & 0 & $0 \%$ & 116 & $40 \%$ \\
\hline P-S115, P-N24 & 0 & $0 \%$ & 116 & $40 \%$ \\
\hline P-S115, RBD & 0 & $0 \%$ & 192 & $66 \%$ \\
\hline P-M1, P-N16 & 0 & $0 \%$ & 71 & $25 \%$ \\
\hline P-M1, P-N24 & 0 & $0 \%$ & 66 & $23 \%$ \\
\hline P-M1, RBD & 0 & $0 \%$ & 111 & $38 \%$ \\
\hline P-N16, P-N24 & 3 & $1 \%$ & 86 & $30 \%$ \\
\hline P-N16, RBD & 0 & $0 \%$ & 133 & $46 \%$ \\
\hline P-N24, RBD & 1 & $0 \%$ & 135 & $47 \%$ \\
\hline
\end{tabular}


Three subgroups were randomly selected from the training group. Subgroup-1, -2 , and -3 comprised (control, COVID-19) sera at $(50,50),(100,100)$, and $(150,150)$, respectively.

Table S4. Impacts of variations in the population used for assay development on response rates for probes and PPHM.

(A) List of response rates for PPHM for the three subgroups.

\begin{tabular}{ccccccc}
\hline \multirow{2}{*}{ Response rate } & \multicolumn{2}{c}{ subgroup-1 } & \multicolumn{2}{c}{ subgroup-2 } & \multicolumn{2}{c}{ subgroup-3 } \\
& Positive & Control & Positive & Control & Positive & Control \\
\hline P-S15 & $30 \%$ & $2 \%$ & $32 \%$ & $3 \%$ & $33 \%$ & $1 \%$ \\
P-S64 & $64 \%$ & $4 \%$ & $59 \%$ & $2 \%$ & $67 \%$ & $2 \%$ \\
P-S82 & $66 \%$ & $6 \%$ & $51 \%$ & $4 \%$ & $58 \%$ & $4 \%$ \\
P-S104 & $50 \%$ & $8 \%$ & $46 \%$ & $4 \%$ & $42 \%$ & $2 \%$ \\
P-S115 & $72 \%$ & $0 \%$ & $69 \%$ & $1 \%$ & $66 \%$ & $1 \%$ \\
P-M1 & $42 \%$ & $0 \%$ & $41 \%$ & $0 \%$ & $39 \%$ & $0 \%$ \\
P-N16 & $54 \%$ & $8 \%$ & $48 \%$ & $3 \%$ & $49 \%$ & $5 \%$ \\
P-N24 & $56 \%$ & $6 \%$ & $38 \%$ & $5 \%$ & $52 \%$ & $3 \%$ \\
RBD & $92 \%$ & $0 \%$ & $82 \%$ & $2 \%$ & $83 \%$ & $0 \%$ \\
\hline
\end{tabular}

(B) List of sensitivity and specificity values under different DMI for the three subgroups.

\begin{tabular}{ccccccc}
\hline \multirow{2}{*}{ cut-off } & \multicolumn{2}{c}{ subgroup-1 } & \multicolumn{2}{c}{ subgroup-2 } & \multicolumn{2}{c}{ subgroup-3 } \\
& Sensitivity & Specificity & Sensitivity & Specificity & Sensitivity & Specificity \\
\hline $\mathrm{DMI} \geq 1$ & $98 \%$ & $74 \%$ & $95 \%$ & $81 \%$ & $95 \%$ & $84 \%$ \\
$\mathrm{DMI} \geq 2$ & $96 \%$ & $94 \%$ & $92 \%$ & $96 \%$ & $93 \%$ & $98 \%$ \\
$\mathrm{DMI} \geq 3$ & $92 \%$ & $98 \%$ & $82 \%$ & $99 \%$ & $87 \%$ & $100 \%$ \\
$\mathrm{DMI} \geq 4$ & $76 \%$ & $100 \%$ & $70 \%$ & $100 \%$ & $73 \%$ & $100 \%$ \\
$\mathrm{DMI} \geq 5$ & $64 \%$ & $100 \%$ & $47 \%$ & $100 \%$ & $55 \%$ & $100 \%$ \\
$\mathrm{DMI} \geq 6$ & $48 \%$ & $100 \%$ & $37 \%$ & $100 \%$ & $41 \%$ & $100 \%$ \\
$\mathrm{DMI} \geq 7$ & $32 \%$ & $100 \%$ & $27 \%$ & $100 \%$ & $26 \%$ & $100 \%$ \\
$\mathrm{DMI} \geq 8$ & $16 \%$ & $100 \%$ & $13 \%$ & $100 \%$ & $14 \%$ & $100 \%$ \\
$\mathrm{DMI} \geq 9$ & $4 \%$ & $100 \%$ & $3 \%$ & $100 \%$ & $4 \%$ & $100 \%$ \\
\hline
\end{tabular}


medRxiv preprint doi: https://doi.org/10.1101/2020.08.11.20172452; this version posted August 11, 2020. The copyright holder for this preprint (which was not certified by peer review) is the author/funder, who has granted medRxiv a license to display the preprint in perpetuity.

All rights reserved. No reuse allowed without permission.

Table S5. Three serum samples were PPHMCovid-19 positive but RBD negative, and CLIA were all borderline positive.

\begin{tabular}{ccccccccccccc}
\hline Serum ID & P-S15 & P-S64 & P-S82 & P-S104 & P-S115 & P-M1 & P-N16 & P-N24 & RBD & IgM & IgG & IgA \\
\hline $59-5$ & 27.74 & 20.83 & 2.56 & 31.59 & 1.85 & 0.86 & 11 & 2.16 & 0 & 0.07 & 1.05 & 0.21 \\
$91-3$ & 21.02 & 37.75 & 0.6 & 35.18 & 1.44 & 0.42 & 4.68 & 1.54 & 3.44 & 0.07 & 1.04 & 0.19 \\
$124-5$ & 37.85 & 36.96 & 7.6 & 29.38 & 3.02 & 3.08 & 6.15 & 5.94 & 2.38 & 2.19 & 1.4 & 0.28 \\
\hline
\end{tabular}


In order to ensure the integrity of the PPHM analyses and to further explore the causes of false negatives and false positives, we categorized 833 tested serum samples into 28 theoretically possible combinations that encompass the four possible combinations of PCR-based and PPHM test results that can result from the seven possible combinations of virus infection and antibody states. Of the 19 combinations for which no serum samples were identified in this cohort: Theoretical category (5) patients (No. 17-20) represent those who have received immediate drug administration upon virus infection; eight groups (No. 1, 2, 5, 13, 21, 22, 25, 26) include all possible false positives; seven groups (No. 7, 8, 12, 15, 16, 24, 27) include all possible scenarios leading to false negative results. While it is the case that false positive PCR results have been reported during this pandemic (9), the low probability of these events is supported by the results observed in this cohort. The high prevalence of false negative results observed in PCR-based assays during the current pandemic, viewed alongside our finding of low prevalence for these combinations in this cohort (No. 7 and 15), together supports the low probability of PPHM false positive results. This robust avoidance against false positive results was also suggested by the absence of group No. 27 samples in this cohort. False negative results such as in groups No. 8, 12,16 , and 24; these are all theoretically possible, but were not observed, most likely due to the cohort size.

Of the eight combinations with serum samples identified in this study, Combination No. 9 in category (3) accounted for the largest portion of positive serum samples; this combination contains the highest probability events. Combination No. 11 includes 178 serum samples with PCR negative but PPHM positive results, which illustrate the advantage of PPHM tests over PCR-based assays. This high prevalence of false negative PCR-based results is attributable to high sampling variation for this testing method, in contrast to serological sampling. Combination No. 6 contains 11 patients that were sampled during the window period of RBD antibody production, but were identified as seropositive by PPHM COVID-19, indicating that PPHM $_{\text {COVID-19 }}$ has improved sensitivity for samples collected at early dpo. Combination No. 28 includes eight patients that exhibited rapidly disappearing antibodies. Combination No. 4, in category (1), accommodates the largest portion of negative serum samples (473 out of 973). Combination No. 3 includes only one PPHM false positive serum sample from Subject 1, which was corrected by simple, auxiliary confirmation tests: Subject 1 was positive for two short peptide probes but had no response to the RBD probe, and no close contact history, indicating a high probability of a false positive by PPHM-1 due to high [mAb]. 
Table S6. Twenty-eight combinations of virus presence, antibody production, PCR and PPHM test results.

\begin{tabular}{|c|c|c|c|c|c|c|}
\hline \multirow{2}{*}{\multicolumn{2}{|c|}{\begin{tabular}{|c|} 
Real status \\
(virus, antibody)
\end{tabular}}} & \multirow{3}{*}{$\begin{array}{c}\begin{array}{c}\text { No. } \\
\text { Group }\end{array} \\
1 \\
\end{array}$} & \multicolumn{2}{|c|}{ Test results } & \multirow{2}{*}{ Characteristic/Explanation } & \multirow{2}{*}{ In our cohort } \\
\hline & & & PCR & PРHM & & \\
\hline \multirow{4}{*}{ (1) } & \multirow{4}{*}{$\begin{array}{c}(-,-) \\
\text { never infected }\end{array}$} & & + & + & PCR false positive; high [mAb] causes PPHM false positive & Not found \\
\hline & & 2 & + & - & PCR false positive & Not found \\
\hline & & 3 & - & + & High [mAb] causes PPHM false positive (other etiology) & SLE patients \\
\hline & & 4 & - & - & Healthy people who have never been infected & Healthy people \\
\hline \multirow{4}{*}{ (2) } & \multirow{4}{*}{$\begin{array}{l}\quad(+,-) \\
\text { viral presence, } \\
\text { window period }\end{array}$} & 5 & + & + & Infected and high $[\mathrm{mAb}]$ causes PPHM false positive & Not found \\
\hline & & 6 & + & - & IgGs stay in window period (mostly dpo $\leq 10$ ) & 11 \\
\hline & & 7 & - & + & $\begin{array}{l}\text { PCR false negative due to non-invasive method and high } \\
{[\mathrm{mAb}] \text { causes PPHM false positive }}\end{array}$ & Not found \\
\hline & & 8 & - & - & PCR false negative due to non-invasive method & Not found \\
\hline \multirow{4}{*}{ (3) } & \multirow{4}{*}{$\begin{array}{c}\quad(+,+) \\
\text { viral presence, } \\
\text { sero-positive }\end{array}$} & 9 & + & + & various dpo & abundant \\
\hline & & 10 & + & - & $\begin{array}{l}\text { PPHM false negative due to low (affinity, concentration), } \\
\text { could be seen by high sensitivity iteration of PPHM }\end{array}$ & 4 \\
\hline & & 11 & - & + & PCR false negative due to viral-absence (sampling too late) & 178 \\
\hline & & 12 & - & - & PCR and PPHM simultaneously false negative & Not found \\
\hline \multirow{4}{*}{ (4) } & \multirow{4}{*}{$\begin{array}{c}(+,-) \\
\text { viral presence, } \\
\text { sero-negative }\end{array}$} & 13 & + & + & high $[\mathrm{mAb}]$ causes PPHM false positive & Not found \\
\hline & & 14 & + & - & Immunodeficiency & 2 \\
\hline & & 15 & - & + & PCR false negative, high $[\mathrm{mAb}]$ causes PPHM false positive & Not found \\
\hline & & 16 & - & - & Immunodeficiency & Not found \\
\hline \multirow{4}{*}{ (5) } & \multirow{4}{*}{$\begin{array}{c}(-,-) \\
\text { viral } \\
\text { clearance, } \\
\text { window period }\end{array}$} & 17 & + & + & PCR false positive, PPHM false positive & Not found \\
\hline & & 18 & + & - & PCR false positive & Not found \\
\hline & & 19 & - & + & PPHM false positive (other etiology) & Not found \\
\hline & & 20 & - & - & IgG development lags behind virus, low dose infection & Not found \\
\hline \multirow{4}{*}{ (6) } & \multirow{4}{*}{$\begin{array}{c}(-,+) \\
\text { viral } \\
\text { clearance, } \\
\text { sero-positive }\end{array}$} & 21 & + & + & PCR false positive & Not found \\
\hline & & 22 & + & - & PCR false positive and PPHM false negative & Not found \\
\hline & & 23 & - & + & Viral clearence, sero-positive & abundant \\
\hline & & 24 & - & - & $\begin{array}{l}\text { PPHM false negative; Our results indicate that there is a } \\
\text { small probability }\end{array}$ & Not found \\
\hline \multirow{4}{*}{ (7) } & \multirow{4}{*}{$\begin{array}{c}(-,-) \\
\text { viral } \\
\text { clearance, } \\
\text { sero-negative }\end{array}$} & 25 & + & + & PCR and PPHM false positive & Not found \\
\hline & & 26 & + & - & PCR false positive & Not found \\
\hline & & 27 & - & + & high $[\mathrm{mAb}]$ causes PPHM false positive & Not found \\
\hline & & 28 & - & - & Sero-negative & Exist \\
\hline
\end{tabular}

